\title{
Phase I Benchmark Control Problem for Seismic Response of Cable-Stayed Bridges
}

\author{
S. J. Dyke ${ }^{1}$; J. M. Caicedo ${ }^{2}$; G. Turan ${ }^{3}$; L. A. Bergman ${ }^{4}$; and S. Hague ${ }^{5}$
}

\begin{abstract}
This paper presents the problem definition for the first generation of benchmark structural control problems for cable-stayed bridges. The benchmark problem is based on the Bill Emerson Memorial Bridge that is currently under construction in Cape Girardeau, Missouri. Construction of the bridge is expected to be completed in 2003. The goal of this study is to provide a testbed for the development of strategies for the control of cable-stayed bridges. Based on detailed drawings, a three-dimensional evaluation model has been developed to represent the complex behavior of the full scale benchmark bridge. The linear evaluation model is developed using the equations of motion generated around the deformed equilibrium position. Evaluation criteria are selected that are consistent with the goals of seismic response control of a cable-stayed bridge. Control constraints ensure that the results are representative of a control implementation on the physical structure. Each participant in this benchmark study is given the task of defining (including devices, sensors, and algorithms), evaluating, and reporting on their proposed control strategies. These strategies may be either passive, active, semiactive, or a combination thereof. A simulation program is provided to facilitate direct comparison of the capabilities and efficiency of the various control strategies. The problem is available through the internet in the form of a set of $M A T L A B^{\circledR}$ programs and includes a sample control design to guide participants through the benchmark problem.
\end{abstract}

DOI: $10.1061 /(A S C E) 0733-9445(2003) 129: 7(857)$

CE Database subject headings: Benchmarks; Seismic response; Bridge, cable-stayed; Control methods; Missouri.

\section{Introduction}

In recent years, benchmark problems have been recognized as a means to compare and contrast various structural control strategies (Caughey 1998). Benchmark structural control problems allow researchers to apply various algorithms, devices, and sensors to a specified problem and make direct comparisons of the results in terms of a specified set of performance objectives. Additionally, these problems may include control constraints and hardware models to more accurately portray the types of implementation issues and constraints one must consider in reality.

All of the benchmark problems considered so far have focused on the control of buildings. The first generation benchmark problem provided a comparison of control algorithms for seismically excited laboratory scale buildings (Spencer et al. 1998a). Re-

\footnotetext{
${ }^{1}$ Associate Professor, Dept. of Civil Engineering, Washington Univ., St. Louis, MO 63130 (corresponding author). E-mail: sdyke@seas.wustl.edu

${ }^{2}$ Graduate Research Assistant and Doctoral Candidate, Dept. of Civil Engineering, Washington Univ., St. Louis, MO 63130.

${ }^{3}$ Assistant Professor, Dept. of Civil Engineering, Izmir Institute of Technology, Izmir, Turkey; formerly, Doctoral Student, Dept. of Civil Engineering, Univ. of Illinois, Urbana, IL 61801.

${ }^{4}$ Professor, Dept. of Aeronautical Engineering, Univ. of Illinois, Urbana, IL 61801.

${ }^{5}$ Associate Vice President, HNTB Corporation, 715 Kirk Drive, Kansas City, MO 64105.

Note. Associate Editor: Billie F. Spencer Jr. Discussion open until December 1, 2003. Separate discussions must be submitted for individual papers. To extend the closing date by one month, a written request must be filed with the ASCE Managing Editor. The manuscript for this paper was submitted for review and possible publication on March 5, 2002; approved on March 5, 2002. This paper is part of the Journal of Structural Engineering, Vol. 129, No. 7, July 1, 2003. CASCE, ISSN $0733-$ 9445/2003/7-857-872/\$18.00.
}

searchers reported their results for this problem at the 1997 ASCE Structures Congress, held in Portland, Oregon. Subsequently, a special issue of Earthquake Engineering and Structural Dynamics was devoted to the results of this benchmark problem. During the Second International Workshop on Structural Control, held in Hong Kong (Chen 1996), working groups were formed to plan the development of a series of benchmark control problems for various classes of civil engineering structures. Two of these working groups concentrated on building structures, and one focused on long-span bridge structures. Subsequently, from the working groups on building systems, second (Spencer et al. 1998b; Yang et al. 1998) and third (Ohton et al. 2003, Yang et al. 2003) generation benchmark control problems buildings were developed.

The working group on bridge control recognized that the control of flexible bridge structures represents a new, difficult, and unique problem, with many complexities in modeling, control design, and implementation. Cable-stayed bridges exhibit complex behavior in which the vertical, translational, and torsional motions are often strongly coupled. Clearly, the control of very flexible bridge structures has not been studied to the same extent as buildings have. As a result, little expertise has been accumulated. Thus, the control of seismically excited cable-stayed bridges presents a challenging problem to the structural control community.

An analytical feasibility study was performed on a wellstudied and documented bridge model to identify and resolve important issues associated with the control of a flexible bridge (Schemmann et al. 1998). Subsequently, a benchmark problem on the control of cable-stayed bridges was initiated. The benchmark problem is based on the cable-stayed bridge currently under construction in Cape Girardeau, Missouri. Instrumentation is being installed in the Emerson bridge and surrounding soil during the 


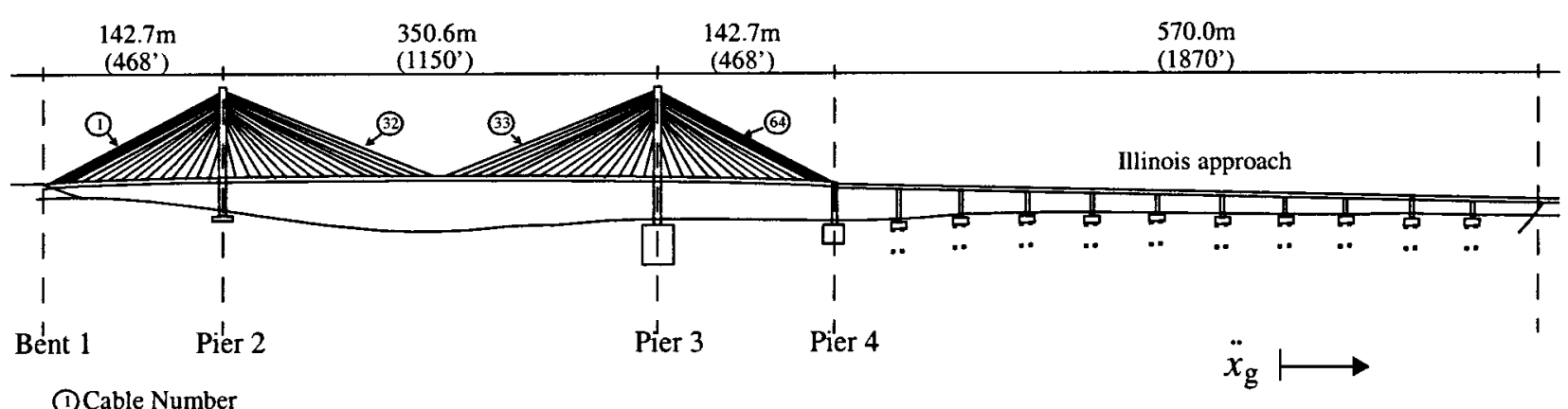

Fig. 1. Drawing of Emerson bridge

construction to evaluate structural behavior and seismic risk (Çelebi 1999).

This paper presents the problem definition for the first generation benchmark structural control problem for cable-stayed bridges. The goal of this study is to provide a testbed for the development of strategies for the effective control of these bridges. Based on detailed drawings of the Emerson bridge, a three-dimensional evaluation model was developed to represent the complex behavior of the full scale benchmark bridge. A linear evaluation model, using the equations of motion generated around the deformed equilibrium position, is deemed appropriate. Because the structure is attached to bedrock, the effects of soilstructure interaction are neglected. The ground acceleration is applied longitudinally and acts simultaneously at all supports. To evaluate the proposed control strategies in terms that are meaningful for cable-stayed bridges, appropriate evaluation criteria and control design constraints are specified within the problem statement. Designers/researchers participating in this benchmark study will define all devices, sensors, and control algorithms used, evaluate them in the context of their proposed control strategies, and report the results. These strategies may be passive, active, semiactive, or a combination thereof. The problem will be made available for downloading on the benchmark web site in the form of a set of MATLAB ${ }^{\circledR}$ equations 〈http://wusceel.cive.wustl.edu/ quake/ $\rangle$. A sample control design is included.

\section{Benchmark Cable-Stayed Bridge}

The cable-stayed bridge used for this benchmark study is the Bill Emerson Memorial Bridge spanning the Mississippi River (between Missouri 74-Illinois 146) near Cape Girardeau, Missouri, designed by the HNTB Corporation (Hague 1997). Seismic considerations were strongly considered in the design of this bridge due to the location of the bridge (the New Madrid seismic zone) and its critical role as a principal crossing of the Mississippi River. In the early stages of the design process, the loading case governing the design was determined to be due to seismic effects.
Earthquake load combinations in accordance with American Association of State Highway and Transportation Officials (AASHTO) division I-A specifications were used in the design. Various designs were considered, including full longitudinal restraint at the tower piers, no longitudinal restraint, and passive isolation. When temperature effects were investigated, it was found that fully restraining the deck in the longitudinal direction would result in unacceptably large stresses. Based on examination of the various designs, it was determined that incorporating force transfer devices would provide the most efficient solution.

Sixteen 6.67 MN (1,500 kip) shock transmission devices are employed in the connection between the tower and the deck. These devices are installed in the longitudinal direction to allow for expansion of the deck due to temperature changes. Under dynamic loads these devices are extremely stiff and are assumed to behave as rigid links. Additionally, earthquake restrainers are employed in the transverse direction at the connection between the towers and the deck, and the deck is restrained in the vertical direction at the towers. The bearings at Bent 1 and Pier 4 are designed to permit longitudinal displacement and rotation about the transverse and vertical axis. Soil-structure interaction is not expected to be significant in this bridge as the foundations of the cable-stayed portion is attached to bedrock.

As shown in Fig. 1, the bridge is composed of two towers, 128 cables, and 12 additional piers in the approach bridge from the Illinois side. It has a total length of $1205.8 \mathrm{~m}$. The main span is $350.6 \mathrm{~m}$ in length, the side spans are $142.7 \mathrm{~m}$ in length, and the approach on the Illinois side is $570 \mathrm{~m}$. A cross section of the deck is shown in Fig. 2. The bridge has four lanes plus two narrower bicycle lanes, for a total width of $29.3 \mathrm{~m}$. The deck is composed of steel beams and prestressed concrete slabs. Steel ASTM A709 grade $50 \mathrm{~W}$ is used, with an $f_{y}$ of $344 \mathrm{MPa}$ (50 ksi). The concrete slabs are made of prestressed concrete with a $f_{c}^{\prime}$ of $41.36 \mathrm{MPa}(6$ $\mathrm{ksi}$ ).

The 128 cables are made of high-strength, low-relaxation steel (ASTM A882 grade 270). The cables are covered with a polyethylene piping to resist corrosion. The $\mathrm{H}$-shaped reinforced concrete

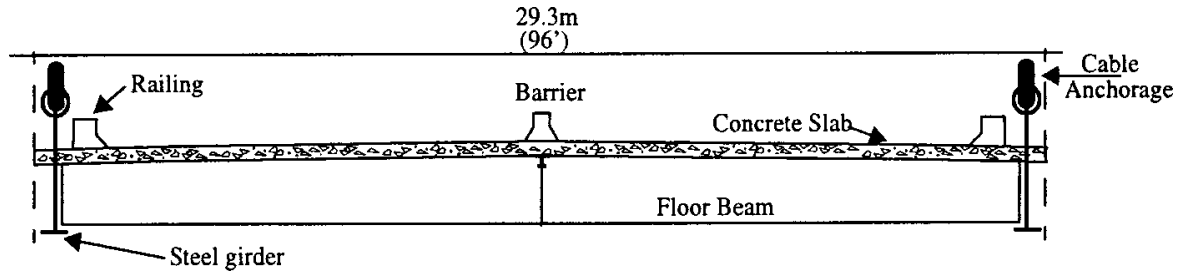

Fig. 2. Cross section of bridge deck 


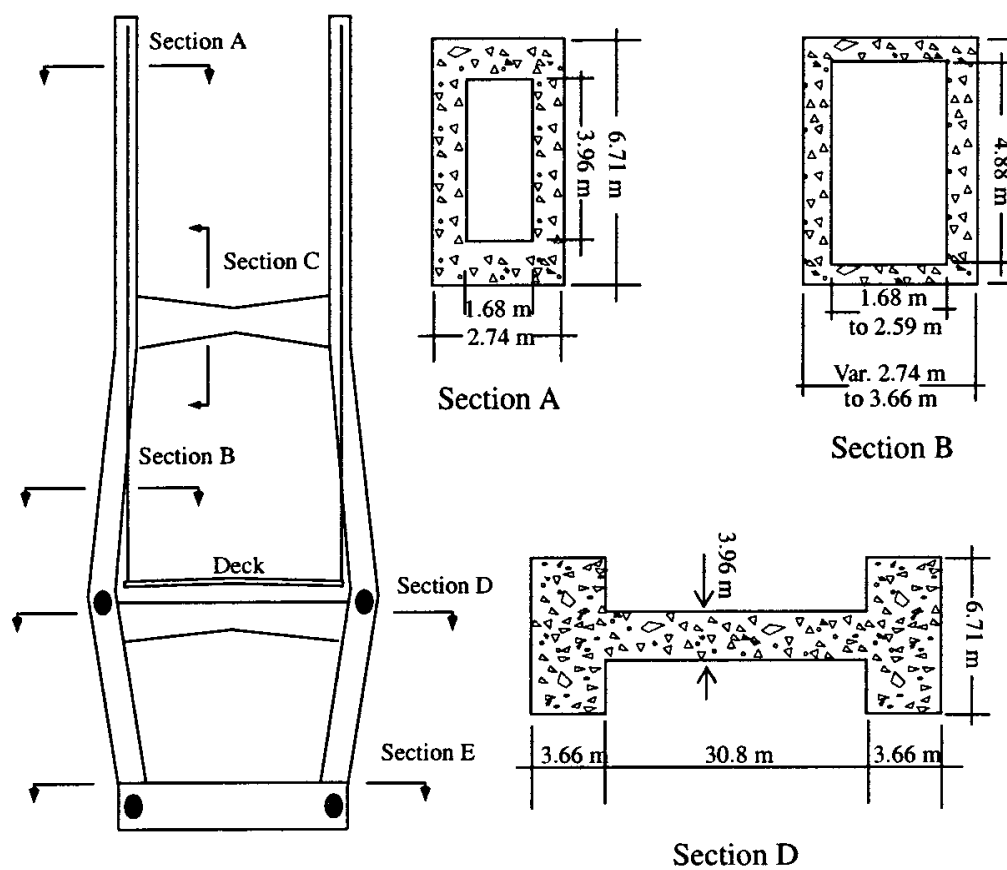

Shear force response locations
Section D

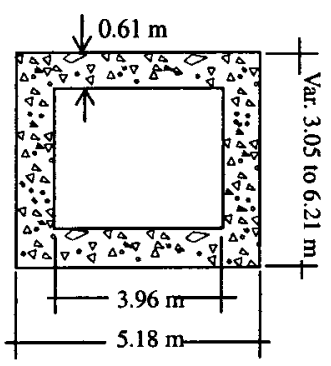

Section C

Fig. 3. Cross sections of towers

towers have a height of $102.4 \mathrm{~m}$ at Pier 2 and $108.5 \mathrm{~m}$ at Pier 3. Each tower supports a total of 64 cables. The cross section of each tower varies five times over the height of the tower, as shown in Fig. 3. The deck consists of a rigid diaphragm made of steel with a slab of concrete at the top.

\section{Evaluation Model}

Based on the description of the Emerson bridge provided in the previous section, a three-dimensional finite-element model of the bridge was developed in MATLAB ${ }^{\circledR}$ (1997). A linear evaluation model is used in this benchmark study. However, the stiffness matrices used in this linear model are those of the structure determined through a nonlinear static analysis corresponding to the deformed state of the bridge with dead loads (Wilson and Gravelle 1991). Additionally, the bridge is assumed to be attached to bedrock, and the effects of soil-structure interaction are neglected. A one-dimensional ground acceleration is applied in the longitudinal direction. This direction is considered to be the most destructive in cable-stayed bridges.

The finite-element model employs beam elements, cable elements, and rigid links. The nonlinear static analysis is performed in $A B A Q U S^{\circledR}$ (1998), and the element mass and stiffness matrices are output to $M A T L A B^{\circledR}$ for assembly. Subsequently, the constraints are applied, and a reduction is performed to reduce the size of the model to something more manageable. These steps are described in the following sections. The first ten frequencies of the evaluation model are $0.2899,0.3699,0.4683,0.5158,0.5812$, 0.6490, 0.6687, 0.6970, 0.7102, and $0.7203 \mathrm{~Hz}$.

To make it possible for designers/researchers to place devices acting longitudinally between the deck and the tower, a modified evaluation model is formed in which the connections between the tower and the deck are disconnected. If a designer/researcher specifies devices at these nodes, the second model will be formed as the evaluation model, and the control devices should connect the deck to the tower. As one would expect, the frequencies of this model are much lower than those of the nominal bridge model. The first ten frequencies of this second model are 0.1618 , $0.2666,0.3723,0.4545,0.5015,0.5650,0.6187,0.6486,0.6965$, and $0.7094 \mathrm{~Hz}$. Note that the uncontrolled structure used as a basis of comparison for the controlled system, corresponds to the former model in which the deck-tower connections are fixed (the dynamically stiff shock transmission devices are present).

\section{Description of Finite-Element Model}

The finite-element model (FEM), shown in Fig. 4, has a total of 579 nodes, 420 rigid links, 162 beam elements, 134 nodal masses, and 128 cable elements. The towers are modeled using 50 nodes, 43 beam elements, and 74 rigid links. Constraints are applied to restrict the deck from moving laterally at Piers 2, 3, and 4. Boundary conditions restrict the motion at Bent 1 to allow longitudinal displacement $(X)$ and rotations about the $Y$ and $Z$ axes. Because the attachment points of the cables to the deck are above the neutral axis of the deck, and the attachment points of the cables to the tower are outside the neutral axis of the tower, rigid links are used to connect the cables to the tower and to the deck (see Fig. 5). The use of rigid links ensures that the length and inclination angle of the cables in the model agree with the drawings. Additionally, the moment induced in the towers by the movement of the cables is taken into consideration with this approach. In the case of variable sections, the average of the section is used for the finite element. The cables are modeled with truss elements. In the finite-element model the nominal tension is assigned to each cable.

The FEM model described above is used directly in cases when the control devices are employed in the longitudinal direction between the deck and tower. If the designer/researcher employs no control device at these locations (in which case the 


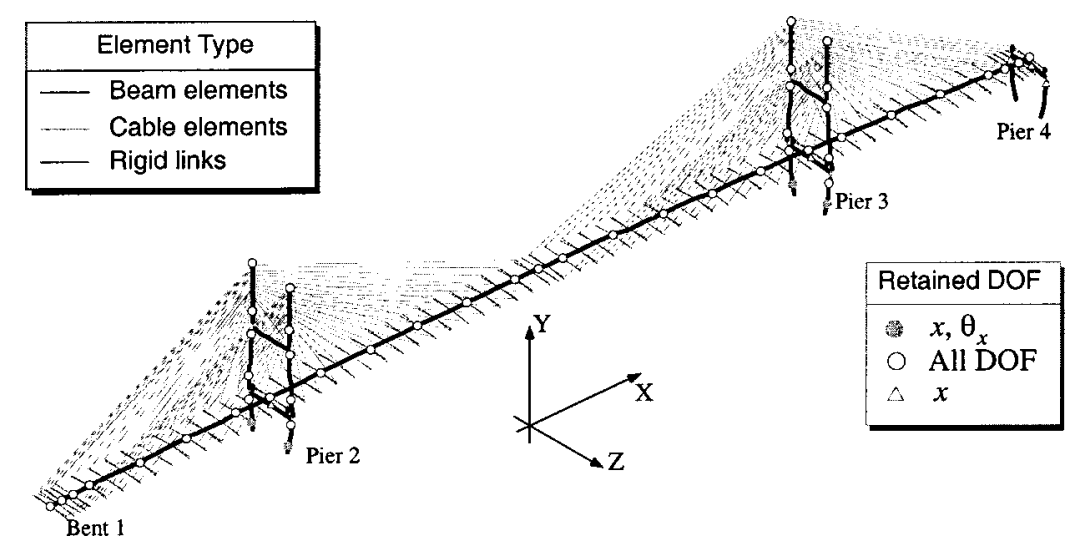

Fig. 4. Finite-element model

shock transmission devices are included), the model is modified by including four longitudinally directed, axially stiff beam elements that force the deck to move with the tower in the longitudinal direction. The uncontrolled structure used as a basis of comparison corresponds to this second case. Note that the program included with the benchmark files determines if the designer/ researcher has placed devices in this location and builds the appropriate FEM model.

Note that the Illinois approach is not included in this model because the bearing at Pier 4 does not restrict longitudinal motion and rotation about the $X$ axis of the bridge, and the Illinois approach has a negligible effect on the dynamics of the cable-stayed portion of the bridge.

\section{Nonlinear Static Analysis}

Cable-stayed bridges exhibit nonlinear behavior due to variations of the catenary shape of the inclined cables, cable tensions that induce compression forces in the deck and towers, and large displacements. A nonlinear static analysis was performed using the commercial finite-element program $A B A Q U S^{\circledR}$, giving the model tangent stiffness matrix at the (deformed) equilibrium position. In $A B A Q U S^{\circledR}$, the $\mathrm{B} 31$ beam element was used for the structural beam element, and the element T3D2 was used for the cable elements.

In modeling the cables, the catenary shape and its variation with the axial force in the cable are modeled using an equivalent elastic modulus (Ernst 1965). The cable element is a largedisplacement truss element that has a modified modulus of elasticity $E_{\text {eq }}$ given by

$$
E_{\mathrm{eq}}=\frac{E_{c}}{1+\left[\frac{\left(w L_{x}\right)^{2} A_{c} E_{c}}{12 T_{c}^{3}}\right]}
$$

where $A_{c}=$ area of the cross section; $T_{c}=$ tension in the cable; $w=$ unit weight, $L_{x}=$ projected length in the $X-Z$ plane; and $E_{c}$ $=$ modulus of elasticity of the material. The cable stiffness contribution to the global stiffness matrix is only applied when the cable is under tension and is omitted otherwise. The cable ele-

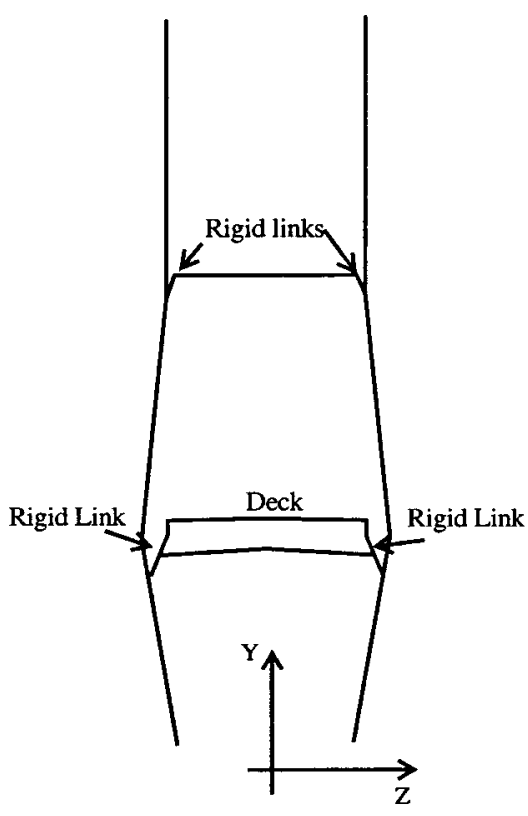

Model of the towers

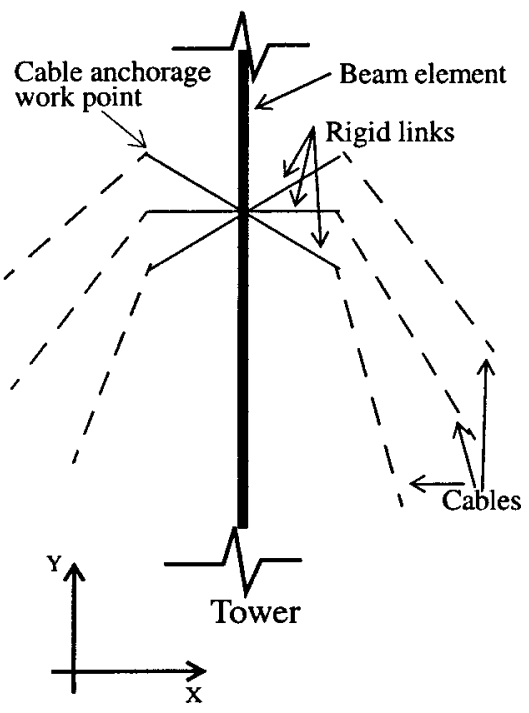

Connection between towers and cables

Fig. 5. Finite-element model of towers 


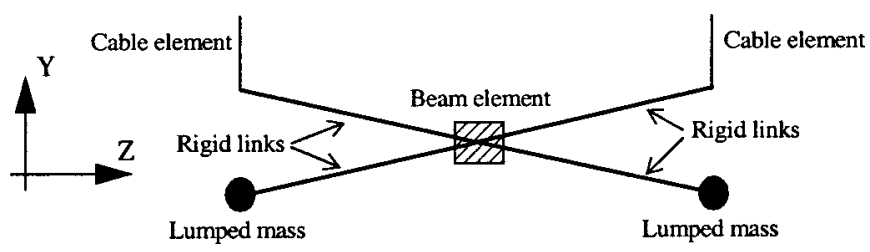

Fig. 6. Finite-element modeling of cross section of deck

ments are modeled as truss elements in $A B A Q U S^{\circledR}$, and their equivalent elastic moduli are used in the nonlinear static analysis.

The deck was modeled using the method described by Wilson and Gravelle (1991). In this approach the deck is modeled as a central beam (the spine) which has no mass. Lumped masses are employed to model the mass of the deck, which are connected to the spine using rigid links (see Fig. 6). The masses are included to more realistically model the torsional response of the deck to lateral loads, and have been shown to be important in the modeling of this structure (Caicedo et al. 2000).

The deck is comprised of two main steel girders along each longitudinal edge of the deck supporting the concrete slab (see Fig. 2). Thus, the deck is treated as a C-shaped section (Wilson and Gravelle 1991). The steel beams are represented by the flanges, and the concrete slab is represented by the web. The axial stiffness of the deck is calculated by converting the area of the concrete slab into an equivalent area $\left(1.844 \mathrm{~m}^{2}\right)$ of steel using the ratio of the two elastic moduli. The moments of inertia about the vertical and transverse axes are also obtained converting the concrete slab to an equivalent steel structure. The inertia of the typical deck section has values of $I_{y y}=160.67 \mathrm{~m}^{4}, I_{z z}=0.6077 \mathrm{~m}^{4}$, and $J_{\text {eq }}=0.0677 \mathrm{~m}^{4}$. The neutral axis is located at $1.77 \mathrm{~m}$ above the bottom of the steel beams.

The calculation of the torsional stiffness of the deck section takes into consideration both pure and warping torsional constants. The pure torsion constant is determined by (Wilson and Gravelle 1991)

$$
J_{t}=\sum_{i=1}^{n} \frac{b_{i} t_{i}^{3}}{3}
$$

where $b_{i}$ and $t_{i}=$ length and thickness of thin sections which make up the deck cross section. The warping constant is calculated as (Bleich 1952)

$$
\Gamma_{w}=\frac{d^{2}}{4}\left\{I_{z z}+e^{2} A\left(1-\frac{d^{2} A}{4 I_{y y}}\right)\right\}
$$

where $d=$ distance between the webs of the two steel beams located along the edges of the deck; $e=$ distance between the neutral axis and the middle of the concrete slab; and $A=$ equivalent cross sectional area. $I_{y y}$ and $I_{z z}=$ moments of inertia of the deck about the $Y$ and $Z$ axes, as determined previously. The torsional stiffness of the deck was obtained using the formula (Wilson and Gravelle 1991)

$$
G_{s} J_{\mathrm{eq}}=G_{s}\left[J+\frac{E_{s} \Gamma_{w} \pi^{2}}{G_{s} L^{2}}\right]
$$

where $G_{s}=$ steel shear modulus of elasticity; $J_{\text {eq }}=$ equivalent torsional constant; $J=$ pure torsion constant; $E_{s}=$ modulus of elasticity of steel; and $L=$ length of the main span.

Calculation of the mass of the deck considers the steel beams, rigid concrete slab, barriers, and railings. The total mass of the deck per unit length was determined to be $2,645.7 \mathrm{~kg} / \mathrm{m}$. To por- tray the behavior of the C-shaped section, the deck is represented as two lumped masses, each having a mass equal to half of the total deck mass, joined to the beam element by a rigid link as shown in Fig. 6. The vertical distance between the lumped mass and the center of the beam is equal to the distance between the shear center and the mass center of the $\mathrm{C}$-shaped section.

Because the mass moment of inertia of the main deck is different than the one induced by the lumped masses, it is necessary to make corrections to those quantities. In the calculation, the correction consists of finding the difference between the mass moment of inertia of the lumped masses and that of the actual deck section's mass moment of inertia. This difference in the mass moment of inertia is added to the node at the center of the deck to achieve the correct value of mass moment of inertia in the section model. The mass moment of inertia of the lumped masses with respect to the $j$ th axis (either the $X, Y$, or $Z$ axis), $I_{j}$, is calculated using the formula

$$
I_{j}=2 M_{l} r^{2}
$$

where $M_{l}=$ mass of each lumped mass and $r=$ perpendicular distance from the mass to each axis. The actual mass moment of inertia of the deck with respect to the $j$ th axis $I_{m j}$ is calculated using

$$
I_{m j}=\sum_{i=1}^{n}\left(I_{m i}+m_{i} r_{i}^{2}\right)
$$

where $I_{m i}=$ mass moment of inertia of each of the component of the deck with respect to its own centroidal axis; $m_{i}=$ mass of each component; and $r_{i}=$ perpendicular distance between the centroid of each component and the $j$ th axis. Thus, the corrected mass moment of inertia of the section becomes

$$
\Delta_{j}=I_{m j}-I_{j}
$$

The value of this parameter about each axis for a typical section of the deck are $\Delta_{X}=-4.43 \cdot 10^{6} \mathrm{~kg} \mathrm{~m}^{2}, \Delta_{Y}=-4.45 \cdot 10^{6} \mathrm{~kg} \mathrm{~m}^{2}$, and $\Delta_{Z}=18.3 \cdot 10^{3} \mathrm{~kg} \mathrm{~m}^{2}$. Negative values indicate that the contribution of the lumped masses to the mass moment of inertia of the section is larger than the mass moment of inertia of the actual section. Thus, a negative value is assigned to the spine to balance the larger value included by the lumped masses when the rigid links are condensed out.

The element mass and tangent stiffness matrices generated in $A B A Q U S^{\circledR}$ are summed at each node to assemble the global stiffness and mass matrices within $M A T L A B^{\circledR}$. The equations are partitioned into active and constrained degrees of freedom (DOFs), and constraints were applied by eliminating the rows and columns associated with fixed boundary conditions, and by condensing out rigid links (applying kinematic constraints). The resulting model has 909 DOFs. The equation of motion for the undamped structural system is

$$
\mathbf{M U ̈}+\mathbf{K U}=-\mathbf{M} \Gamma \ddot{x}_{g}+\Lambda \mathbf{f}
$$

where $\ddot{\mathbf{U}}=$ second time derivative of the response vector $\mathbf{U} ; \mathbf{M}$ and $\mathbf{K}=$ mass and stiffness matrices of the structure; $\mathbf{f}(\mathrm{N})$ =vector of control force inputs; $\ddot{x}_{\mathrm{g}}\left(\mathrm{m} / \mathrm{sec}^{2}\right)=$ longitudinal ground acceleration; $\Gamma=$ vector of zeros and ones relating the ground acceleration to the bridge DOFs in the longitudinal direction of the bridge; and $\Lambda=$ vector defining how the force(s) produced by the control device(s) enter the structure. 


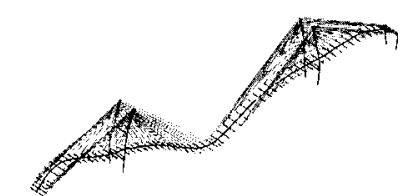

First Mode Shape (Vertical, $.2899 \mathrm{~Hz}$ )
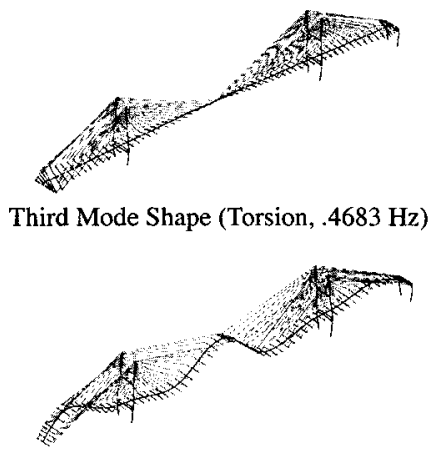

Fifth Mode Shape (Vertical, $.5812 \mathrm{~Hz}$ )

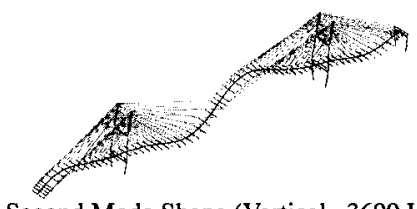

Second Mode Shape (Vertical, $.3699 \mathrm{~Hz}$ )

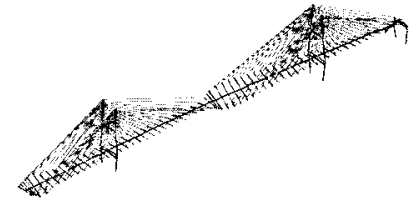

Fourth Mode Shape (Torsion, $.5158 \mathrm{~Hz}$ )

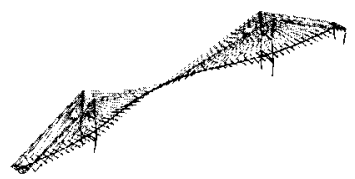

Sixth Mode Shape (Lateral+Torsional, .6490 Hz)

Fig. 7. Representative mode shapes of bridge evaluation model

\section{Model Reduction}

The model resulting from the finite-element formulation has a large number of degrees-of-freedom and high-frequency dynamics. Thus, some assumptions are made regarding the behavior of the bridge to make the model more manageable for dynamic simulation while retaining the fundamental behavior of the bridge. The active DOF retained in the model include: (1) the nodes at the top of each tower; (2) the lowest nodes at which cables are connected on each tower; (3) nodes at the joints of the towers; (4) nodes or DOFs of elements whose shear and overturning moments are among the design criteria; (5) approximately every third node of the bridge deck; and (6) rotational DOFs about the longitudinal and vertical axis of all spinal deck nodes. These locations are indicated in the finite-element model in Fig. 4.

Static condensation is performed by partitioning the mass and stiffness matrices into active and dependent DOF, determining the static transformation matrix, and finding the transformed mass, stiffness, and input coefficient matrices, as discussed by Craig (1981). Application of this reduction scheme to the full model of the bridge resulted in a 419 DOF reduced order model. The first 100 natural frequencies of the reduced model (up to $3.5 \mathrm{~Hz}$ ) are in good agreement with those of the 909 DOF structure.

The damping in the system is defined based on the assumption of modal damping. The damping matrix was developed by assigning $3 \%$ of critical damping to each mode. This value was selected to be consistent with assumptions made during the design of the bridge. The resulting equation of motion for the damped structural system is

$$
\hat{\mathbf{M}} \ddot{\mathbf{U}}+\hat{\mathbf{C}} \hat{\mathbf{U}}+\hat{\mathbf{K}} \hat{\mathbf{U}}=-\hat{\Gamma} \ddot{x}_{g}+\hat{\Lambda} \mathbf{f}
$$

where $\hat{\mathbf{U}}=$ displacement vector of active DOFs. This model is termed the evaluation model. It is considered to portray the actual dynamics of the bridge and will be used to evaluate various control systems. Note that this model always includes the effects of the shock transmission devices, which constrain longitudinal motion. The evaluation model and earthquake inputs are fixed for this benchmark problem. A representative sample of the mode shapes is shown in Fig. 7.

\section{Analysis Tool}

The linear model of the bridge system is simulated using a version of the analysis tool developed by Ohtori and Spencer (1999) for linear systems. This tool allows the user to implement the compiled C code from within the MATLAB ${ }^{\circledR}$ environment through a SIMULINK ${ }^{\circledR}$ (1997) block to simulate the responses of a seismically excited structural system. This tool solved the incremental equations of motion using the Newmark- $\beta$ method in combination with the pseudo-force method. To use the code, one must define the mass, stiffness, and damping matrices for the evaluation structure [ $\hat{\mathbf{M}}, \hat{\mathbf{C}}$, and $\hat{\mathbf{K}}$ in Eq. (9)], as well as the matrices defining the inputs and outputs of the structural system. The input and output matrices are found using the state space form of Eq. (9) given by

$$
\dot{\mathbf{x}}=\mathbf{A}_{e} \mathbf{x}+\mathbf{B}_{e}\left[\begin{array}{c}
\ddot{x}_{g} \\
\mathbf{f}
\end{array}\right] \quad \mathbf{y}=\mathbf{C}_{e} \mathbf{x}+\mathbf{D}_{e}\left[\begin{array}{c}
\ddot{x}_{g} \\
\mathbf{f}
\end{array}\right]
$$

where $\mathbf{x}=\left[\hat{\mathbf{U}}^{T} \hat{\mathbf{U}}^{T}\right]^{T}=$ state vector; $\mathbf{A}_{e}=$ state matrix; and $\mathbf{B}_{e}, \mathbf{C}_{e}$, and $\mathbf{D}_{e}=$ determined by the inputs and outputs selected by the designer/researcher.

\section{Control Design Problem Statement}

As stated previously the researcher/designer must define the sensors, devices, and algorithms to be used in his/her control strategy. These must be defined in specific forms to properly interface with the benchmark bridge model. The sensors and control devices interface with the bridge model through measurement and connection outputs, designated $\mathbf{y}_{m}$ and $\mathbf{y}_{\mathrm{c}}$, respectively. Additionally participants define the components of the evaluation output vector, designated $\mathbf{y}_{e}$. The components of $\mathbf{y}_{m}, \mathbf{y}_{c}$, and $\mathbf{y}_{e}$ are specified within an input/output file provided with the benchmark problem statement. A MATLAB ${ }^{\circledR}$ graphical user interface is provided to simplify this procedure. However, this information can be directly inserted into the input/output file as well.

\section{Control System Components}

The sensors must be defined to measure the outputs of the evaluation model. Researchers/designers must develop models for the sensors which must take the following form: 


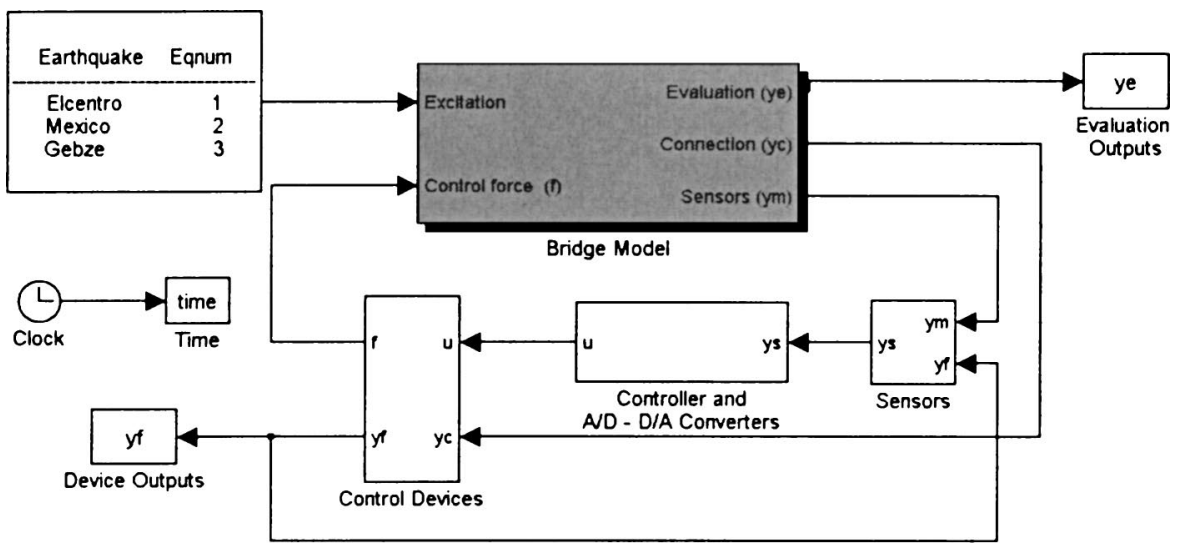

Fig. 8. SIMULINK ${ }^{\circledR}$ model for benchmark cable-stayed bridge problem

$$
\begin{aligned}
\dot{\mathbf{x}}^{s} & =\mathbf{g}_{1}\left(\mathbf{x}^{s}, \mathbf{y}_{m}, \mathbf{y}_{f}, t\right) \\
\mathbf{y}^{s} & =\mathbf{g}_{2}\left(\mathbf{x}^{s}, \mathbf{y}_{m}, \mathbf{y}_{f}, t\right)
\end{aligned}
$$

where $\mathbf{x}^{s}=$ continuous-time state vector of the sensor(s); and $\mathbf{y}^{s}$ $=$ continuous-time output of the sensor(s) [Volts]. $\mathbf{y}_{f}$ is the continuous-time output vector from the control device model [see Eqs. (17-19)], which may include forces produced by individual control devices, device stroke, device acceleration, is used for evaluation of the control strategy and is available for feed-back in the control algorithm.

Passive, active, and semiactive control devices (or combinations thereof) may be used in designing control systems. For active/semiactive control systems, the associated discrete-time control algorithm must take the form

$$
\begin{gathered}
\mathbf{x}_{k+1}^{c}=\mathbf{g}_{3}\left(\mathbf{x}_{k}^{c}, \mathbf{y}_{k}^{s}, k\right) \\
\mathbf{u}_{k}=\mathbf{g}_{4}\left(\mathbf{x}_{k}^{c}, \mathbf{y}_{k}^{s}, k\right)
\end{gathered}
$$

where $\mathbf{x}_{k}^{c}=$ discrete-time state vector of the control algorithm at each sampling time $t=k T ; \mathbf{y}_{k}^{s}=$ discrete-time input to the control algorithm from the sensors [which should be discretized in time and quantized to represent an analog to digital (A/D) converter]; and $\mathbf{u}_{k}=$ discrete-time control command from the control algorithm.

Dynamic models of the control devices selected by the researcher/designer are not required for this benchmark study. Ideal control devices may be assumed. Note that the program allows designers/researchers to place control devices at constrained nodes although errors will result in the simulated responses. To interface with the benchmark bridge model the control device model(s) must take the form

$$
\begin{gathered}
\mathbf{f}=\mathbf{g}_{5}\left(\mathbf{y}_{\mathrm{c}}, \mathbf{u}_{k}, t\right) \\
\mathbf{y}_{f}=\mathbf{g}_{6}\left(\mathbf{y}_{c}, \mathbf{u}_{k}, t\right)
\end{gathered}
$$

where $\mathbf{y}_{c}$ contains the continuous-time responses from the evaluation model that influence the control forces and $\mathbf{f}$ $=$ continuous-time force output of the control device(s) applied to the structure (in units of [kN]). Researchers/designers who choose to employ dynamic models of their control devices should use the form

$$
\begin{array}{r}
\dot{\mathbf{x}}^{d}=\mathbf{g}_{7}\left(\mathbf{x}^{d}, \mathbf{y}_{c}, \mathbf{u}_{k}, t\right) \\
\mathbf{f}=\mathbf{g}_{8}\left(\mathbf{x}^{d}, \mathbf{y}_{c}, \mathbf{u}_{k}, t\right) \\
\mathbf{y}_{f}=\mathbf{g}_{9}\left(\mathbf{x}^{d}, \mathbf{y}_{c}, \mathbf{u}_{k}, t\right)
\end{array}
$$

where $\mathbf{x}^{d}$ is the continuous-time state vector of the control device. Fig. 8 provides the SIMULINK ${ }^{\circledR}$ model used for evaluation of proposed control strategies. Designers/researchers should follow the procedure summarized in Fig. 9 to develop and evaluate their designs.

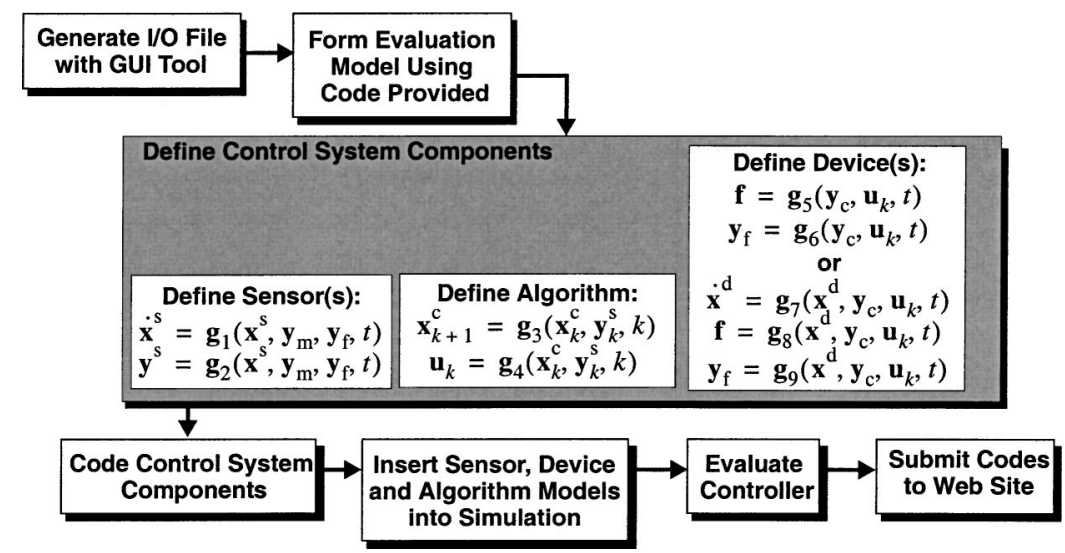

Fig. 9. Flow chart of benchmark solution procedure 
Table 1. Uncontrolled Maximum Responses for Performance Criteria Calculations

\begin{tabular}{|c|c|c|c|c|}
\hline Response & Definition & El Centro, U.S.A. & Mexico City, Mexico & Gebze, Turkey \\
\hline$F_{0 b}^{\max }(\mathrm{kN})$ & $\max _{i, t}\left|F_{0 b i}(t)\right|$ & $4.8782 e+4$ & $1.1181 e+4$ & $3.0848 e+4$ \\
\hline$F_{0 d}^{\max }(\mathrm{kN})$ & $\max _{i, t}\left|F_{0 d i}(t)\right|$ & $4.6712 e+3$ & $1.5248 e+3$ & $3.1497 e+3$ \\
\hline$M_{0 b}^{\max }(\mathrm{kN} \mathrm{m})$ & $\max _{i, t}\left|M_{0 b i}(t)\right|$ & $1.0271 e+6$ & $1.9824 e+5$ & $6.9779 e+5$ \\
\hline$M_{0 d}^{\max }(\mathrm{kN} \mathrm{m})$ & $\max _{i, t}\left|M_{0 d i}(t)\right|$ & $2.2054 e+5$ & $8.6701 e+4$ & $1.0927 e+5$ \\
\hline$x_{0 b}(\mathrm{~m})$ & $\max _{i, t}\left|x_{0 b i}(t)\right|$ & $9.7583 e-2$ & $2.4324 e-2$ & $7.1916 e-2$ \\
\hline$\left\|F_{0 b}(t)\right\|(\mathrm{kN})$ & $\max _{i}\left\|F_{b i}(t)\right\|$ & $5.2647 e+3$ & $1.4741 e+3$ & $2.6088 e+3$ \\
\hline$\left\|F_{0 d}(t)\right\|(\mathrm{kN})$ & $\max _{i}\left\|F_{d i}(t)\right\|$ & $4.5607 e+2$ & $1.889 e+2$ & $2.3124 e+2$ \\
\hline$\left\|M_{0 b}(t)\right\|(\mathrm{kN} \mathrm{m})$ & $\max _{i}\left\|M_{b i}(t)\right\|$ & $1.1628 e+5$ & $3.1467 e+4$ & $5.7793 e+4$ \\
\hline$\left\|M_{0 d}(t)\right\|(\mathrm{kN} \mathrm{m})$ & $\max _{i}\left\|M_{d i}(t)\right\|$ & $2.0128 e+4$ & $6.9306 e+3$ & $9.5070 e+3$ \\
\hline$x_{0}^{\max }(\mathrm{m})$ & $\max _{t}\left|x_{0}(t)\right|$ & 0.14862 & $4.8302 e-2$ & 0.13117 \\
\hline$\dot{x}_{0}^{\max }(\mathrm{m} / \mathrm{s})$ & $\max _{t}\left|\dot{x}_{0}(t)\right|$ & 1.1795 & $0.32172 e$ & 0.61848 \\
\hline
\end{tabular}

\section{GUI Tool}

A MATLAB ${ }^{\circledR}$-based graphical user interface (GUI) tool has been developed to aid the researcher/designer in generating the input/ output information for the evaluation model. The graphical user interface allows the user to select the node numbers defining the evaluation outputs $\mathbf{y}_{e}$, the connection outputs $\mathbf{y}_{c}$, and the measured outputs $\mathbf{y}_{m}$ for use in each control strategy. The location of the control devices may also be specified within the GUI. Once the control system setup is specified, the user may choose to generate the evaluation model from within the GUI or from the $M A T L A B^{\circledR}$ command window.

\section{Evaluation Criteria}

For cable-stayed bridges subjected to earthquake loading, critical responses are related to the structural integrity of the bridge rather than to serviceability issues. Thus, in evaluating the performance of each control algorithm, the shear forces and moments in the towers at key locations (see Fig. 3) must be considered. Additionally, the tension in the cables should never approach zero, and should remain close to the nominal pretension.

A set of 18 criteria have been developed to evaluate the capabilities of each control strategy. For each control design, the evaluation criteria should be evaluated for each of three earthquake records provided in the benchmark problem: (1) El Centro-The North-South component recorded at the Imperial Valley Irrigation District substation in El Centro, California, during the Imperial Valley, California earthquake of May, 18, 1940; (2) Mexico City - Recorded at the Galeta de Campos station with site Geology of Meta-Andesite Breccia in September 19, 1985; and (3) Gebze, Turkey-The North-South component of the Kocaeli earthquake recorded at the Gebze Tubitak Marmara Arastirma Merkezi on Aug. 17, 1999. The Mexico City earthquake is selected because geological studies have indicated that the Cape Girardeau region is similar to Mexico City. The El Centro and Gebze earthquakes allow for the researcher/designer to test his/her control strategies on earthquakes with different char- acteristics. Each earthquake is at or below the design peak ground acceleration level for the bridge of $0.36 \mathrm{~g}$ 's.

The first two evaluation criteria are nondimensionalized measures of the shear force at key locations in the towers. The elevation of these key locations correspond to the tower base and the deck level (see Fig. 3). The latter criterion was selected because this elevation corresponds to a drastic reduction in the crosssectional area of the towers. Evaluation criteria one and two are given by

$$
\left.\begin{array}{l}
J_{1}=\max _{\substack{\text { El Centro } \\
\text { Mexico City } \\
\text { Gebze }}}\left\{\frac{\max _{i, t}\left|F_{b i}(t)\right|}{F_{0 b}^{\max }}\right\} \\
J_{2}=\underset{\substack{\text { Eax Centro } \\
\text { Mexico City } \\
\text { Gebze }}}{\max _{0 b}\left|F_{d i}(t)\right|} \\
F_{0 d}^{\max }
\end{array}\right\}
$$

where $F_{b i}(t)=$ base shear at the $i$ th tower; $F_{0 b}^{\max }=\max _{i, t}\left|F_{0 b i}(t)\right|$ $=$ maximum uncontrolled base shear (of the values at the two towers); $F_{d i}(t)=$ shear at the deck level in the $i$ th tower (see Fig. 3); $F_{0 d}^{\max }=\max _{i, t}\left|F_{0 d i}(t)\right|=$ maximum uncontrolled shear at the deck level, and $|\cdot|$ indicates absolute value. The values of $F_{0 b}^{\max }, F_{0 d}^{\max }$, and all other values used to normalize the evaluation criteria, are provided in Table 1.

The second set of evaluation criterion are nondimensionalized measures of the moments in the towers at the same key locations, given by

$$
J_{3}=\max _{\substack{\text { El Centro } \\ \text { Mexico City } \\ \text { Gebze }}}\left\{\frac{\max _{i, t}\left|M_{b i}(t)\right|}{M_{0 b}^{\max }}\right\}
$$




$$
J_{4}=\max _{\substack{\text { El Centro } \\ \text { Mexico City } \\ \text { Gebze }}}\left\{\frac{\max _{i, t}\left|M_{d i}(t)\right|}{M_{0 d}^{\max }}\right\}
$$

where $M_{b i}(t)=$ moment at the base of the $i$ th tower; $M_{0 b}^{\max }$ $=\max \left|M_{0 b i}(t)\right|=$ maximum uncontrolled moment at the base of the $i, t$

two towers; $M_{d i}(t)=$ moment at the deck level in the $i$ th tower; and $M_{0 d}^{\max }=\max _{i, t}\left|M_{0 d i}(t)\right|=$ maximum uncontrolled moment at the deck level in the two towers.

The fifth evaluation criterion is a nondimensionalized measure of the deviation of the tension in the stay cables from the nominal pretension, given by

$$
J_{5}=\max _{\substack{\text { El Centro } \\ \text { Mexico City } \\ \text { Gebze }}}\left\{\max _{i, t}\left|\frac{T_{a i}(t)-T_{0 i}}{T_{0 i}}\right|\right\}
$$

where $T_{0 i}=$ nominal pretension in the $i$ th cable and $T_{a i}(t)$ $=$ actual tension in the cable as a function of time. This criterion is selected to reduce the likelihood of failure or unseating of the cables.

The Sixth evaluation criterion is a measure of the peak deck displacement at Bent 1 and Pier 4.

$$
J_{6}=\underset{\substack{\text { El Centro } \\ \text { Mexico City } \\ \text { Gebze }}}{\max }\left\{\max _{i, t}\left|\frac{x_{b i}(t)}{x_{0 b}}\right|\right\}
$$

where $x_{b i}(t)=$ displacement of the deck at these locations and $x_{0 b}=$ maximum of the uncontrolled deck response. This criterion is included to consider the likelihood of impact of the deck at these locations.

The seventh and eighth evaluation criteria are nondimensionalized measures of the normed values of the base shear and shear at the deck level in each of the towers, respectively, given by

$$
\left.\begin{array}{c}
J_{7}=\max _{\substack{\text { El Centro } \\
\text { Mexico City } \\
\text { Gebze }}}\left\{\frac{\max _{i}\left\|F_{b i}(t)\right\|}{\left\|F_{0 b}(t)\right\|}\right\} \\
J_{8}=\underset{\substack{\text { El Centro } \\
\text { Mexico City } \\
\text { Gebze }}}{\max }\left\{\frac{\max _{i}\left\|F_{d i}(t)\right\|}{\left\|F_{0 d}(t)\right\|}\right.
\end{array}\right\}
$$

where $\left\|F_{0 b}(t)\right\|=$ maximum of the normed value of the uncontrolled base shear of the two towers and $\left\|F_{0 d}(t)\right\|=$ maximum of the normed value of the uncontrolled shear at the deck level of the tower. The normed value of the response, denoted $\|\cdot\|$, is defined as

$$
\|\cdot\| \equiv \sqrt{\frac{1}{t_{f}} \int_{0}^{t_{f}}(\cdot)^{2} d t}
$$

where $t_{f}$ is defined as the time required for the response to attenuate.

The ninth and tenth evaluation criteria are nondimensionalized measures of the normed values of the overturning moment and moment at the deck level in each of the towers, respectively, given by

$$
\begin{gathered}
J_{9}=\max _{\substack{\text { El Centro } \\
\text { Mexico City } \\
\text { Gebze }}}\left\{\frac{\max _{i}\left\|M_{b i}(t)\right\|}{\left\|M_{0 b}(t)\right\|}\right\} \\
J_{10}=\underset{\substack{\text { El Centro } \\
\text { Mexico City } \\
\text { Gebze }}}{\max _{i}\left\|M_{d i}(t)\right\|}
\end{gathered}
$$

where $\left\|M_{0 b}(t)\right\|=$ maximum of the normed value of the uncontrolled moment at the base of the two towers and $\left\|M_{0 d}(t)\right\|$ $=$ maximum of the normed value of the uncontrolled moment at the deck level of the two towers.

The 11th evaluation criterion is a nondimensionalized measure of the normed value of the deviation of the tension in the stay cables from the nominal pretension, given by

$$
J_{11}=\max _{\substack{\text { El Centro } \\ \text { Mexico City } \\ \text { Gebze }}}\left\{\max _{i, t} \frac{\left\|T_{a i}(t)-T_{0 i}\right\|}{T_{0 i}}\right\}
$$

where $T_{0 i}=$ existing pretension in the $i$ th cable and $T_{a i}(t)$ $=$ actual tension in the $i$ th cable as a function of time.

The 12th evaluation criterion deals with the maximum force generated by the control device(s) and is described as

$$
J_{12}=\max _{\substack{\text { El Centro } \\ \text { Mexico City } \\ \text { Gebze }}}\left\{\max _{i, t}\left(\frac{f_{i}(t)}{W}\right)\right\}
$$

where $f_{i}(t)=$ force generated by the $i$ th control device over the time history of each earthquake and $W=510,000 \mathrm{kN}$ $(114,640 \mathrm{kips})=$ seismic weight of bridge based on the mass of the superstructure (not including the foundation).

The 13th criterion is based on the maximum stroke of the control device(s). This performance measure is given as

$$
J_{13}=\max _{\substack{\text { El Centro } \\ \text { Mexico City } \\ \text { Gebze }}}\left\{\max _{i, t}\left(\frac{\left|y_{i}^{d}(t)\right|}{x_{0}^{\max }}\right)\right\}
$$

where $y_{i}^{d}(t)=$ stroke of the $i$ th control device over the time histories of each earthquake, and $x_{0}^{\max }=$ maximum uncontrolled displacement at the top of the towers relative to the ground. When devices are used that do not have an associated stroke (e.g., tuned liquid dampers), the researcher/designer should assume this evaluation constraint is zero.

The 14th evaluation criterion is a nondimensionalized measure of the maximum instantaneous power required to control the bridge, and is defined as

$$
J_{14}=\max _{\substack{\text { El Centro } \\ \text { Mexico City } \\ \text { Gebze }}}\left\{\frac{\max ^{t}\left[\Sigma_{i} P_{i}(t)\right]}{\dot{x}_{0}^{\max } W}\right\}
$$

where $P_{i}(t)=$ measure of the instantaneous power required by the $i$ th control device; and $\dot{x}_{0}^{\max }=$ peak uncontrolled velocity at the top of the towers relative to the ground. Values for $\dot{x}_{0}^{\max }$ are provided in Table 1 for each of the earthquakes specified. For active control devices, $P_{i}(t) \equiv\left|\dot{y}_{i}^{d}(t) f_{i}(t)\right|$, where $\dot{y}_{i}^{d}(t)=$ velocity of the $i$ th control device. When semiactive devices are employed, $P_{i}(t)$ is the actual power required to operate the device. For passive control devices, this criterion is zero. 
Table 2. Summary of Evaluation Criteria

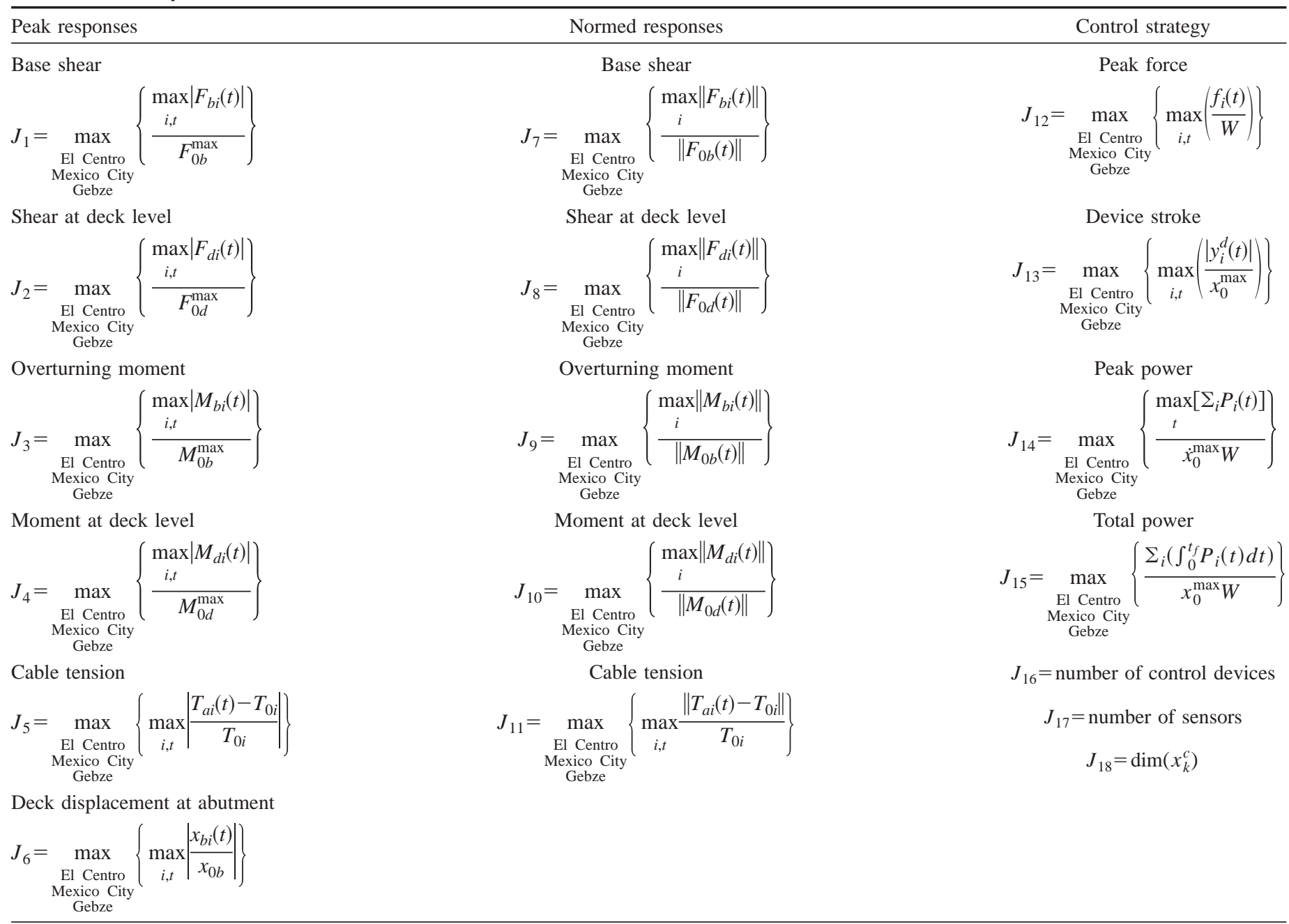

The 15 th evaluation criterion is a nondimensionalized measure of the total power required to control the bridge, and is defined as

$$
J_{15}=\max _{\substack{\text { El Centro } \\ \text { Mexico City } \\ \text { Gebze }}}\left\{\frac{\sum_{i}\left(\int_{0}^{t_{f}} P_{i}(t) d t\right)}{x_{0}^{\max } W}\right\}
$$

This criterion is zero when passive device(s) are used.

The 16th evaluation criterion $J_{16}$ is a measure of the total number of control devices required in the control system to control the bridge. The 17 th evaluation criterion $J_{17}$ is a measure of the total number of sensors required for the proposed control strategy. The final evaluation criterion provides a measure of the resources required to implement the control algorithm and is given by

$$
J_{18}=\operatorname{dim}\left(\mathbf{x}_{k}^{c}\right)
$$

where $\mathbf{x}_{k}^{c}=$ discrete-time state vector of the control algorithm given in Eq. (13).

A summary of the evaluation criteria is provided in Table 2. The values of the uncontrolled responses for the three earthquakes are provided in Table 1 . All 18 criteria and all three earthquakes should be reported for each proposed design. However, designers/ researchers are encouraged to include additional criteria in their results if, through these criteria, their results demonstrate an overall desirable quality. An example of such a situation might be a control system that performs well for one type of earthquake but marginally for other earthquakes used to evaluate the control strategy.

\section{Control Strategy Implementation Constraints and Procedures}

To allow researchers/designers to compare and contrast various control strategies, each of the controllers must be subjected to a uniform set of constraints and procedures, specified below:

1. The measured outputs directly available for use in determining the control action are the absolute accelerations of the bridge at the nodes of the finite-element model, and control device outputs which are readily available (e.g., device stroke, force, or absolute acceleration). Although absolute velocity measurements are not available, appropriate filtering of the absolute accelerations may be performed to approximate the velocity responses as described in Spencer et al. (1998a,b). If pseudo-velocity measurements are used, the designer/researcher should specify the filter used in the sensor model [see Eqs. (11) and (12)];

2. The digitally implemented controller has a sampling time of $T=0.02 \mathrm{~s}$. This sampling time should be set equal to the integration step of the simulation;

3. The $\mathrm{A} / \mathrm{D}$ and digital-to-analog (D/A) converters on the digital controller have 16-bit precision and a span of $\pm 10 \mathrm{~V}$; 
4. Each of the measured responses contains an (RMS) noise of $0.03 \mathrm{~V}$, which is approximately $0.3 \%$ of the full span of the A/D converters. The measurement noises are modeled as Gaussian rectangular pulse processes with a pulse width equal to the integration step;

5. Currently, available real-time control implementation hardware is impressive. However, such hardware has limitations and the number of calculations in the control scheme should be kept to a reasonable number. The designer/researcher should justify that the proposed algorithm(s) can be implemented with currently available computing hardware;

6. The control algorithm is required to be stable. The stability robustness for each proposed active control design should be discussed by each researcher/designer;

7. The performance criteria of each researcher/designer's controller should be evaluated using the evaluation model, the provided SIMULINK ${ }^{\circledR}$ diagram, and each of the earthquake records provided in the benchmark problem;

8. Designers/researchers are requested to submit a program that will produce each of the evaluation criterion specified in this problem statement. The resulting controllers will be included on the web page for the first generation benchmark bridge control problem. Instructions on the formatting of these files are included in the information provided with the benchmark files;

9. Designers/researchers are required to submit the SIMULINK ${ }^{\circledR}$ blocks used for controller performance evaluations. For each controller, one sensor block, one control algorithm block, and one control device block should be submitted;

10. Tension in the stay cables should remain within a recommended range of allowable values. A lower bound is necessary to ensure that unseating of a cable does not occur, and an upper bound provides a factor of safety to prevent failure of the cable. The tension in the $i$ th cable may not exceed $0.7 T_{f i}$ or fall below $0.2 T_{f i}$, where $T_{f i}$ is the tension that would cause failure of the $i$ th cable. Values for $T_{f i}$ are provided in the MATLAB ${ }^{\circledR}$ codes;

11. Because the D/A converters have a range of $\pm 10 \mathrm{~V}$, the command signal to each control device has a constraint of $\max _{t}\left|u_{i}^{k}(t)\right| \leqslant 10 \mathrm{~V}$, where $u_{i}^{k}(t)$ is the $i$ th component of the control signal;

12. Each control device employed should be described in terms of the maximum force that can be generated. Researchers/ designers must demonstrate that this force constraint is met during each of the earthquakes;

13. Any additional constraints that are unique to each control scheme should also be reported (i.e., maximum stroke of control device, maximum velocity of control device, etc.). Control devices should be selected to allow for expansion of the briege due to temperature effects.

\section{Sample Control System Design}

The following sample control design serves as a guide to the participants in this study and will lead them through the constraints and design criteria that are set forth in the previous sections. Accelerometers and displacement transducers are used for feedback to the control algorithm. The sample control system employs a total of 24 hydraulic actuators located between the deck and abutment and the deck and the towers and oriented to apply forces longitudinally ( $X$ direction). Therefore, to implement this controller one would replace the shock transmission devices

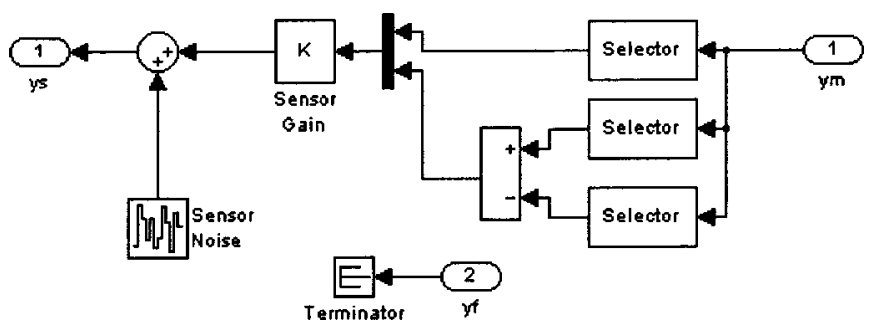

Fig. 10. SIMULINK ${ }^{\circledR}$ block: Sensors

in the bridge with hydraulic actuators. Thus, the modified model is used for the control design. For simplicity, the control devices act as ideal force actuators, and actuator dynamics and controlstructure interaction is neglected. This sample has been prepared to serve as a guide to designers/researchers and is not intended to be competitive.

\section{Sensors}

Five accelerometers and four displacement sensors are employed in the sample control system. Four accelerometers are located on top of the tower legs (Nodes 240, 248, 353, 361), and one is located on the deck at midspan (Node 34). All accelerometers are positioned to measure the absolute acceleration in the global $X$ direction, which is longitudinal to the bridge. The natural frequency of the selected accelerometers are assumed to have a value that is at least an order of magnitude higher than the highest natural frequency we are interested in controlling. Thus the selected accelerometers have a flat frequency response to approximately 3,000 rad/s (i.e., a constant magnitude and phase), and sensor dynamics can be neglected. Two displacement sensors are positioned between the deck and Pier 2 [node pairs $(84,313)$, $(151,314)]$ and two displacement sensors are located between the deck and Pier 3 [node pairs $(118,428),(185,429)$ ]. All displacement measurements are obtained in the longitudinal direction to the bridge (global $X$ direction).

To ensure that the accelerations and displacement measured on the bridge are within the range of the A/D converters, accelerometers are selected with a sensitivity of $7 \mathrm{~V} / \mathrm{g}$ (i.e., $7 \mathrm{~V}$ $=9.81 \mathrm{~m} / \mathrm{s}^{2}$ ) and a displacement sensors have a sensitivity of 30 $\mathrm{V} / \mathrm{m}$ (i.e., $10 \mathrm{~V}=0.33 \mathrm{~m}$ ). Thus the sensor system is defined in the form of Eqs. (11) and (12) as

$$
\mathbf{y}^{s}=\mathbf{D}_{s} \mathbf{y}_{m}+\mathbf{v}
$$

where $\mathbf{y}^{s}=$ vector of the measured responses in volts; $\mathbf{y}_{m}$ $=$ vector of measured continuous-time responses in physical units (i.e., $\left[\mathrm{m} / \mathrm{sec}^{2}\right]$ for accelerations and $[\mathrm{m}]$ for displacements); and $\mathbf{v}$ is the measurement noise, and

$$
\mathbf{D}_{s}=\left[\begin{array}{cc}
\mathbf{I}_{5 \times 5} G_{a} & \mathbf{0} \\
\mathbf{0} & \mathbf{I}_{4 \times 4} G_{d}
\end{array}\right]
$$

where $G_{a}=0.714 \mathrm{~V} /\left(\mathrm{m} / \mathrm{sec}^{2}\right)=$ sensor gain for acceleration and $G_{d}=30 \mathrm{~V} / \mathrm{m}$. The sensor block is represented in the SIMULINK ${ }^{\circledR}$ block shown in Fig. 10. Note that in the sample controller the device outputs are not measured, and therefore the corresponding signal $\mathbf{y}_{f}$ is not connected to the system, although it is available for participants. Finally, noise with an RMS value of $0.03 \mathrm{~V}$ is added to the acceleration signal.

\section{Control Devices}

A total of 24 hydraulic actuators are placed, eight between the deck and Pier 2, eight between the deck and Pier 3, four between 


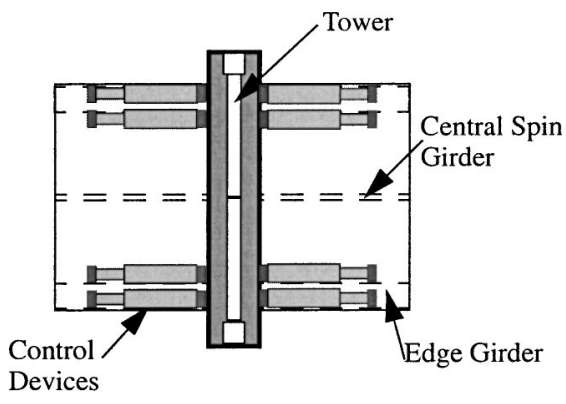

Fig. 11. Typical tower actuator implementation

the deck and Bent 1, and four between the deck and Pier 4. The control devices are oriented to apply forces longitudinally. Four actuators are located between each of the following pairs of nodes on Piers 2 and 3: (84, 313), (151, 314), (118, 428), (185, 429); two actuators are located between each of the following pairs of nodes on Bent 1 and Pier 4: (68, ground), (135, ground), (134, $444),(201,440)$. The actuators have a capacity of $1,000 \mathrm{kN}$. For this sample control design actuator dynamics are neglected and the actuator is considered to be ideal.

Fig. 11 shows the typical device layout. The equations describing the forces produced by the actuators in the form of Eqs. (15) and (16) are

$$
\mathbf{f}=\mathbf{K}_{f} \mathbf{u} \text { and } \mathbf{y}_{f}=\mathbf{D}_{d} \mathbf{u}
$$

where $\mathbf{D}_{d}=100 \mathrm{kN} / \mathrm{V}(10 \mathrm{~V}=1,000 \mathrm{kN})=$ gain of the actuator and $\mathbf{K}_{f}=$ matrix that accounts for the gain of the actuator (i.e., the relationship between the input voltage and the desired control force) as well as the fact that multiple actuators are used at each actuator location. For the sample control design $\mathbf{K}_{f}$ takes the form

$$
\mathbf{K}_{f}=\left[\begin{array}{ccc}
2 \mathbf{I}_{1 \times 1} & & \mathbf{0} \\
& 4 \mathbf{I}_{2 \times 2} & \\
\mathbf{0} & & 2 \mathbf{I}_{1 \times 1}
\end{array}\right] \mathbf{D}_{d}=\mathbf{G}_{\mathrm{dev}} \mathbf{D}_{d}
$$

Fig. 12 shows the SIMULINK ${ }^{\circledR}$ control device block. For the sample control design there are no connection inputs to the control devices because the actuator dynamics are neglected and the control device model does not require any inputs from the structure.

\section{Control Design Model}

A reduced order model of the system is developed for control design. This model, designated the design model, is formed from the evaluation model and has 30 states. The resulting model has the same outputs as the evaluation model [see Eq. (10)]. The reduced order model is formed in MATLAB ${ }^{\circledR}$ by forming a balanced realization of the system and condensing out the states with

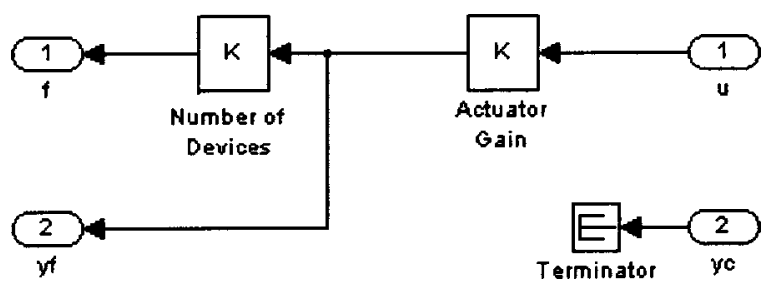

Fig. 12. SIMULINK ${ }^{\circledR}$ block: Control devices relatively small controllability and observability grammians. The resulting state space system is represented as follows

$$
\begin{aligned}
\dot{\mathbf{x}}^{r} & =\mathbf{A}_{r} \mathbf{x}^{r}+\mathbf{B}_{r} \ddot{x}_{g}+\mathbf{E}_{r} \mathbf{u} \\
\mathbf{z} & =\mathbf{C}_{r}^{z} \mathbf{x}^{d}+\mathbf{D}_{r}^{z} \ddot{x}_{g}+\mathbf{F}_{r}^{z} \mathbf{u} \\
\mathbf{y}_{m} & =\mathbf{C}_{r}^{y} \mathbf{x}^{d}+\mathbf{D}_{r}^{y} \ddot{x}_{g}+\mathbf{F}_{r}^{y} \mathbf{u}
\end{aligned}
$$

where $\mathbf{x}^{d}=$ design state vector; $\mathbf{A}_{r}$ and $\mathbf{B}_{r}=$ system matrices; and $\mathbf{z}=$ regulated output vector, which is obtained from the mapping matrices $\mathbf{C}_{r}^{z}, \mathbf{D}_{r}^{z}$, and $\mathbf{F}_{r}^{z}$. Similarly, $\mathbf{y}_{m}$ is the measurement vector, which is obtained from the mapping matrices $\mathbf{C}_{r}^{y}, \mathbf{D}_{r}^{y}$, and $\mathbf{F}_{r}^{y}$. The gains of the sensors and control devices [i.e., $\mathbf{D}_{s}$ in Eq. (38) and $\mathbf{D}_{d}$ in Eq. (40), respectively], as well as the matrix defining the number of control devices $\left[\mathbf{G}_{\mathrm{dev}}\right.$ in Eq. (40)], are incorporated into this model for control design.

\section{Control Algorithm}

The sample controller employs a linear quadratic Gaussian (LQG) control design. For this design, $\ddot{x}_{g}$ is taken to be a stationary white noise, and an infinite horizon performance index is chosen that weights the displacements of the deck at Bent 1 and Pier 4, i.e.,

$$
J=\lim _{\tau \rightarrow \infty} \frac{1}{\tau} E\left[\int_{0}^{\tau}\left\{\left(\mathbf{C}_{r}^{z} \mathbf{x}^{r}+\mathbf{D}_{r}^{z} \mathbf{u}\right)^{T} \mathbf{Q}\left(\mathbf{C}_{r}^{z} \mathbf{x}^{r}+\mathbf{D}_{r}^{z} \mathbf{u}\right)+\mathbf{u}^{T} \mathbf{R} \mathbf{u}\right\}(d t)\right]
$$

where $\mathbf{R}=[8 \times 8]$ identity matrix and the weighting on the regulated outputs was chosen to be $\mathbf{Q}=10^{3} \mathbf{I}_{4 \times 4}$. Further, the measurement noise is assumed to be identically distributed, statistically independent Gaussian white noise processes, and $S_{\ddot{x}_{g} \ddot{x}_{g}} / S_{v_{i} v_{i}}=\gamma=25$.

The control and estimation problems are considered separately according to the separation principle (Stengel 1986; Skelton 1988), yielding a controller of the form

$$
\mathbf{u}=-\mathbf{K}_{\mathbf{u}} \hat{\mathbf{x}}^{r}
$$

where $\hat{\mathbf{x}}^{r}=$ Kalman filter estimate of the state vector based on the reduced order model. By the certainty equivalence principle (Stengel 1986; Skelton 1988), $\mathbf{K}_{\mathbf{u}}$ is the full state feedback gain matrix for the deterministic regulator problem given by

$$
\mathbf{K}_{\mathbf{u}}=\widetilde{\mathbf{R}}^{-1}\left(\widetilde{\mathbf{N}}+\mathbf{B}_{d}^{T} \mathbf{P}\right)
$$

where $\underset{\sim}{\mathbf{P}}=$ solution of the algebraic Riccati equation given by

$$
\mathbf{0}=\underset{\sim}{\mathbf{P}} \widetilde{\mathbf{A}}+\widetilde{\mathbf{A}}^{T} \underset{\sim}{\mathbf{P}}-\underset{\sim}{\mathbf{P}} \mathbf{B}_{d} \widetilde{\mathbf{R}}^{-1} \mathbf{B}_{d}^{T} \mathbf{P}+\widetilde{\mathbf{Q}}
$$

and

$$
\begin{gathered}
\widetilde{\mathbf{Q}}=\mathbf{C}_{d}^{z^{T}} \mathbf{Q} \mathbf{C}_{d}^{z}-\widetilde{\mathbf{N}} \widetilde{\mathbf{R}}^{-1} \widetilde{\mathbf{N}}^{T} \\
\widetilde{\mathbf{N}}=\mathbf{C}_{d}^{z^{T}} \mathbf{Q} \mathbf{D}_{d}^{z} \\
\widetilde{\mathbf{R}}=\mathbf{R}+\mathbf{D}_{d}^{z^{T}} \mathbf{Q} \mathbf{D}_{d}^{z} \\
\widetilde{\mathbf{A}}=\mathbf{A}_{d}-\mathbf{B}_{d} \widetilde{\mathbf{R}}^{-1} \widetilde{\mathbf{N}}^{T}
\end{gathered}
$$

Calculations to determine $\mathbf{K}_{\mathbf{u}}$ were done using the MATLAB ${ }^{\circledR}$ (1997) routine lqry. $m$ within the control toolbox.

The Kalman filter optimal estimator is given by

$$
\begin{aligned}
& \hat{\mathbf{x}}^{r}=\mathbf{A}_{r} \hat{\mathbf{x}}^{r}+\mathbf{B}_{r} \mathbf{u}+\mathbf{L}\left(\mathbf{y}_{m}-\mathbf{C}_{r}^{y} \hat{\mathbf{x}}^{r}-\mathbf{D}_{r}^{y} \mathbf{u}\right) \\
& \mathbf{L}=\left[\underset{\sim}{\mathbf{R}^{-1}}\left(\gamma \mathbf{F}_{r}^{y} \mathbf{E}_{r}^{T}+\mathbf{C}_{r}^{y} \mathbf{S}\right)\right]^{T}
\end{aligned}
$$

where $\mathbf{S}=$ solution of the algebraic Riccati equation given by 


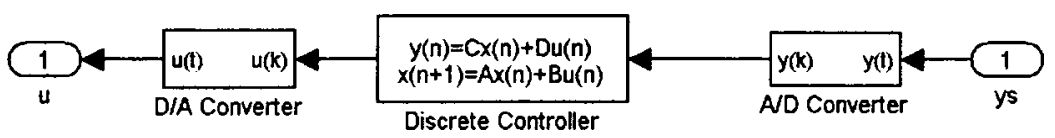

Fig. 13. SIMULINK ${ }^{\circledR}$ block: Control algorithm

Table 3. Evaluation Criteria for Sample Controller

\begin{tabular}{lccccccccc}
\hline Value & El Centro & Mexico & Gebze & Max & Value & El Centro & Mexico & Gebze & Max \\
\hline$J_{1}$ & 0.38706 & 0.46110 & 0.45488 & 0.46110 & $J_{10}$ & 0.882351 & 1.1036 & 1.4573 & 1.4573 \\
$J_{2}$ & 1.0665 & 1.3645 & 1.3828 & 1.3828 & $J_{11}$ & $2.8015 e-2$ & $1.0252 e-2$ & $1.7065 e-2$ & $2.8015 e-2$ \\
$J_{3}$ & 0.29392 & 0.58477 & 0.44515 & 0.58477 & $J_{12}$ & $1.5828 e-3$ & $5.9575 e-4$ & $1.7264 e-3$ & $1.7264 e-3$ \\
$J_{4}$ & 0.62525 & 0.61401 & 1.2246 & 1.2246 & $J_{13}$ & 0.78713 & 1.1723 & 1.9566 & 1.9566 \\
$J_{5}$ & 0.18580 & $7.697 e-2$ & 0.14832 & 0.18580 & $J_{14}$ & $2.6938 e-3$ & $1.8124 e-3$ & $7.3198 e-3$ & $7.3198 e-3$ \\
$J_{6}$ & 1.1988 & 2.3278 & 3.5686 & 3.5686 & $J_{15}$ & $4.2756 e-4$ & $2.4143 e-4$ & $6.9029 e-4$ & $6.9029 e-4$ \\
$J_{7}$ & 0.22603 & 0.39931 & 0.32365 & 0.39931 & $J_{16}$ & 24 & 24 & 24 & 9 \\
$J_{8}$ & 1.1805 & 1.2109 & 1.4403 & 1.4403 & $J_{17}$ & 9 & 30 & 9 & 30 \\
$J_{9}$ & 0.26697 & 0.41903 & 0.45564 & 0.45564 & $J_{18}$ & 30 & 30 & 30 \\
\hline
\end{tabular}
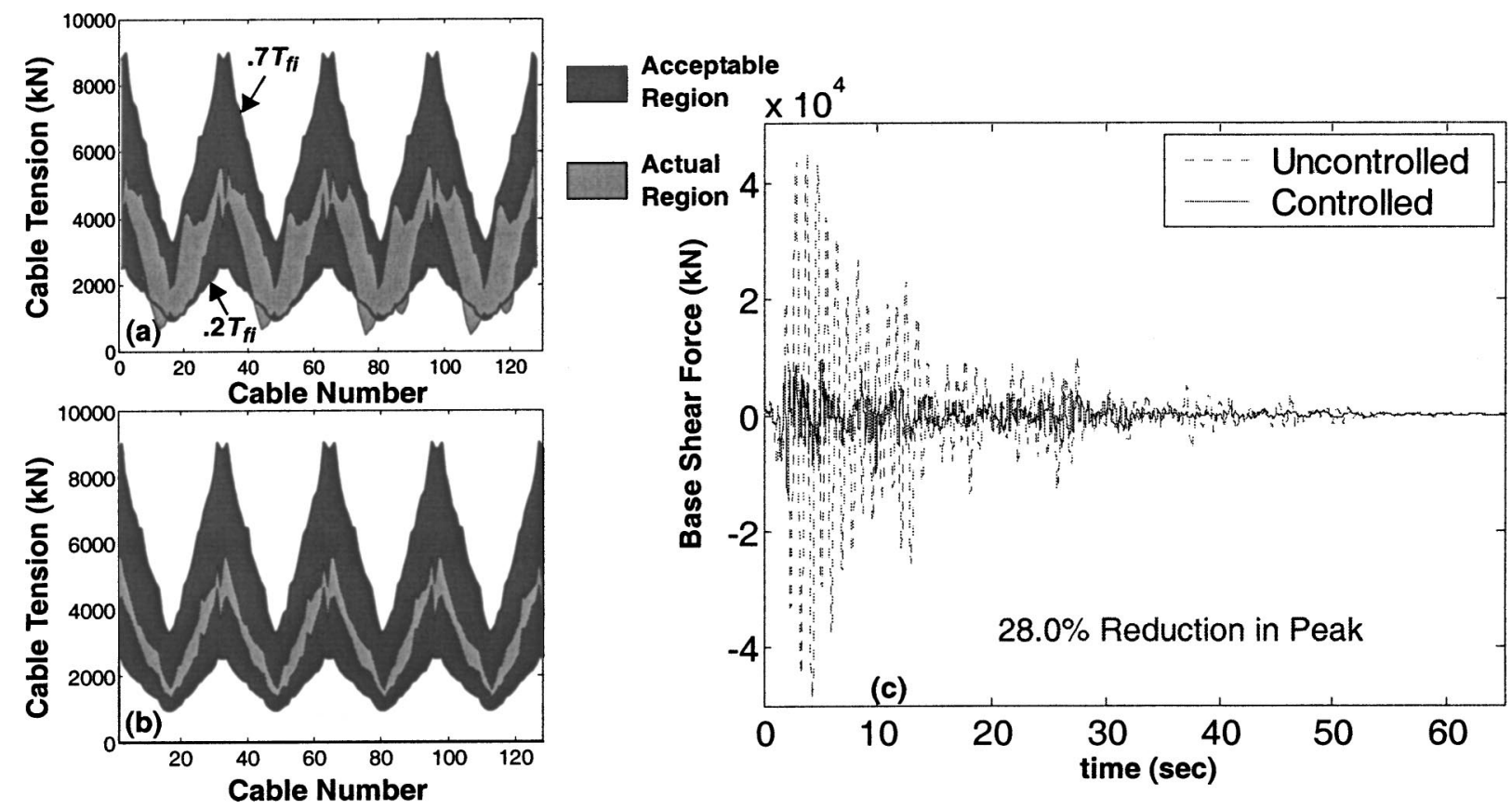

Fig. 14. Simulated responses to El Centro earthquake: (a) uncontrolled cable tensions; (b) controlled cable tensions; and (c) uncontrolled and controlled base shear force record (Pier 2).

$$
\mathbf{0}=\mathbf{S} \underset{\sim}{\mathbf{A}}+\underset{\sim}{\mathbf{A}^{T}} \mathbf{S}-\mathbf{S G S}+\underset{\sim}{\mathbf{H}}
$$

and

$$
\begin{gathered}
\underset{\sim}{\mathbf{A}}=\mathbf{A}_{r}^{T}-\mathbf{C}_{r}^{y^{T}} \underset{\sim}{\mathbf{R}^{-1}}\left(\gamma \mathbf{F}_{r}^{y} \mathbf{E}_{r}^{y^{T}}\right) \\
\underset{\sim}{\mathbf{G}}=\mathbf{C}_{r}^{y^{T}}{\underset{\sim}{\mathbf{R}}}^{-1} \mathbf{C}_{r}^{y} \\
\underset{\sim}{\mathbf{H}}=\gamma \underset{r}{\mathbf{E}_{r}} \mathbf{E}_{r}^{T}-\gamma^{2} \mathbf{E}_{r} \mathbf{F}_{r}^{y^{T}}{\underset{\sim}{\mathbf{R}}}^{-1} \mathbf{F}_{r}^{y} \mathbf{E}_{r}^{T} \\
\underset{\sim}{\mathbf{R}}=\mathbf{I}+\gamma \mathbf{F}_{r}^{y} \mathbf{F}_{r}^{y^{T}}
\end{gathered}
$$

Calculations to determine $\mathbf{L}$ were done using the $M A T L A B^{\circledR}$ routine lqew. $m$ within the control toolbox.
For implementation on a digital computer, the controller is put in the form of Eqs. (13)-(14) using the bilinear transformation (Antoniou 1993; Quast et al. 1995) yielding the following compensator:

$$
\begin{gathered}
\mathbf{x}_{k+1}^{c}=\mathbf{A}_{c} \mathbf{x}_{k}^{c}+\mathbf{B}_{c} \mathbf{y}_{k}^{s} \\
\mathbf{u}_{k}=\mathbf{C}_{c} \mathbf{x}_{k}^{c}+\mathbf{D}_{c} \mathbf{y}_{k}^{s}
\end{gathered}
$$

Calculations to determine the discrete-time compensator were performed in MATLAB ${ }^{\circledR}$ using the $c 2 d m . m$ routine within the control toolbox.

The SIMULINK ${ }^{\circledR}$ block shown in Fig. 13 is used to represent 
Table 4. Actuator Requirements for Sample Control Strategy

\begin{tabular}{lcccc}
\hline Response & El Centro & Mexico & Gebze & Max \\
\hline Force $(\mathrm{kN})$ & 807.22 & 303.83 & 880.45 & 880.45 \\
Stroke $(\mathrm{m})$ & 0.1170 & 0.0566 & 0.2566 & 0.2566 \\
Vel $(\mathrm{m} / \mathrm{s})$ & 0.6850 & 0.3245 & 0.5644 & 0.6850 \\
\hline
\end{tabular}

the sample control algorithm in the simulation. To represent the hardware used to implement this algorithm on a digital computer, an analog-to-digital converter (A/D) and a digital-to-analog converter (D/A) are modeled. The models consist of a quantizer and a saturator as described in the Control Strategy Implementation Constraints and Procedures.

\section{Evaluation of Sample Control Design}

The closed-loop response is evaluated for the three earthquakes specified. Table 3 shows the values of the evaluation criteria in Eqs. (20)-(36). The responses of the controlled bridge are compared to those of the uncontrolled bridge for the El Centro earthquake in Fig. 14. The left plot shows the maximum and minimum cable tension as a function of cable number. The dark region provides the acceptable range of cable tensions as specified in the control constraints (between the $0.2 T_{f i}$ and $0.7 T_{f i}$ ), and the lighter region provides a graphical description of the actual minimum and maximum cable tension. Note that the uncontrolled cable tension falls below the lower bound in cables near the tower for this earthquake. However, the controlled cable tension is well within the bounds. Additionally a graph of the base shear at Pier 2 is provided to demonstrate the reduction that the controller can achieve. To demonstrate the feasibility of this controller, peak values of the force, stroke, and velocity are provided for each earthquake in Table 4. Note that the force, velocity, and displacement requirements are feasible for a device of this size.

\section{Closure}

A benchmark problem on the seismic control of cable-stayed bridges has been developed based on the Bill Emerson Memorial Bridge in Cape Girardeau, Missouri spanning the Mississippi River. For Phase I of the benchmark problem, a finite-element model has been developed, and evaluation criteria are provided that are consistent with the goals of controlling cable-stayed bridges subjected to earthquake loading. The evaluation model of the Emerson cable-stayed bridge, the MATLAB ${ }^{\circledR}$ (1997) files used for the sample control design, and the simulation model, are available at $\langle$ http://wusceel.cive.wustl.edu/quake/〉. If you cannot access the World Wide Web or have questions regarding the benchmark problem please contact Dr. Shirley Dyke via e-mail at sdyke@seas.wustl.edu.

Phase II of this study will focus on more complex issues regarding the control of cable-stayed bridges such as transverse and multi-support excitations.

\section{Acknowledgments}

This research is supported in part by the National Science Foundation Grant No. CMS 97-33272 (Dr. S.C. Liu, Program Director). The writers would like to thank Mr. Shyam Gupta of the Missouri Department of Transportation and Mr. Bill Strossener of the FHWA for pertinent information on the Emerson Bridge. The helpful advice of Professor Yozo Fujino (University of Tokyo), Professor Masato Abe (University of Tokyo), Professor Hirokazu Iemura (Kyoto University), Professor Joel Conte (University of California, Los Angeles), Professor Petros Voulgaris (University of Illinois), Professor Fabio Biondini (Politecnico di Milano), and Gerry Pollok (ABAQUS ${ }^{\circledR}$ ), as well as additional comments provided by members of the ASCE/IASC Task Group on Benchmark Structural Control Problems and other members of the structural control community, are gratefully acknowledged.

\section{Notation}

The following symbols are used in this paper:

$\mathbf{A}_{c}, \mathbf{B}_{c}, \mathbf{C}_{c}, \mathbf{D}_{c}$

$=$ discrete controller system matrices;

$\mathbf{A}_{e}, \mathbf{B}_{e}, \mathbf{C}_{e}, \mathbf{D}_{e}$

$=$ state space matrices of evaluation model;

$\mathbf{A}_{r}, \mathbf{B}_{r}, \mathbf{C}_{r}^{z}, \mathbf{D}_{r}^{z}, \mathbf{C}_{r}^{y}, \mathbf{D}_{r}^{y}, \mathbf{E}_{r}, \mathbf{F}_{r}^{z}, \mathbf{F}_{r}^{y}$

$=$ reduced model system matrices in which superscript $\mathbf{z}$ denotes regulated outputs, and $\mathbf{y}$ denotes measured outputs;

$\underset{\sim}{\mathbf{A}}=$ matrix used in solution of algebraic Riccati equation for Kalman estimator;

$A=$ equivalent area of cross section of deck;

$A_{c}=$ cable cross-sectional area;

$b_{i}=$ long dimension of each element of deck cross section used to obtain pure torsional constant of deck, $J_{t}$;

$\hat{\mathbf{C}}=$ damping matrix of evaluation model;

$\mathbf{D}_{s}=$ matrix describing model of sensors in sample controller;

$\mathbf{D}_{d}=$ matrix gain of control devices;

$d=$ distance between web of two edge girders;

$E_{c}=$ modulus of elasticity of cables;

$E_{\mathrm{eq}}=$ equivalent modulus of elasticity of cables including catenary effects;

$E_{s}=$ modulus of elasticity of steel;

$e=$ distance between neutral axis of deck and center of concrete slab;

$F_{0 b}^{\max }=$ maximum uncontrolled base shear at towers;

$F_{b i}(t)=$ base shear at $i$ th tower;

$\left\|F_{0 b}(t)\right\|=$ maximum of normed value of uncontrolled base shear at two towers;

$F_{d i}(t)=$ shear force at deck level in $i$ th tower;

$\left\|F_{0 d}(t)\right\|=$ maximum of normed value of uncontrolled shear at deck level for towers;

$F_{0 d}^{\max }=$ maximum uncontrolled shear force at deck level of two towers;

$\mathbf{f}=$ continuous-time force output of control devices;

$f_{i}(t)=$ force generated by $i$ th control device;

$f_{c}^{\prime}=28$ day compressive strength of concrete;

$\mathbf{G}=$ matrix used in solution of algebraic Riccati equation for Kalman estimator;

$G_{s}=$ shear modulus of steel;

$G_{a}, G_{d}=$ sensitivity of acceleration and displacement sensors in sample controller;

$G_{\mathrm{dev}}=$ gain factor to account for number of control devices in control device model;

$\mathbf{g}_{1}, \mathbf{g}_{2}=$ models for interfacing with sensors;

$\mathbf{g}_{3}, \mathbf{g}_{4}=$ models for interfacing with active/ semiactive control algorithm; 
$\mathbf{g}_{5}, \mathbf{g}_{6}=$ models for interfacing with control device model (without device model);

$\mathbf{g}_{7}, \mathbf{g}_{8}, \mathbf{g}_{9}=$ models for interfacing with control device model (including device models);

$\underset{\sim}{\mathbf{H}}=$ matrix used in solution of algebraic Riccati equation for Kalman estimator;

$I_{i}=$ mass moment of inertia of $i$ th lumped mass in calculation of correction of rotational mass inertia of deck;

$I_{j}=$ mass moment of inertia of lumped masses in deck with respect to $j$ th axis $(X, Y$, or $Z)$;

$I_{m i}=$ mass moment of inertia of each of $i$ th component of deck with respect to its centroidal axis;

$I_{m j}=$ mass moment of inertia of section with respect to $j$ th axis;

$I_{z z}, I_{y y}=$ moments of inertia of bridge sections about $Z$ and $Y$ axes, respectively;

$J=$ performance index;

$J_{t}=$ pure torsion constant of deck;

$J_{\text {eq }}=$ equivalent torsion constant of deck taking into consideration pure torsion and warping torsion;

$J_{1}, J_{2}, \ldots, J_{18}=$ evaluation criteria;

$\mathbf{K}, \mathbf{M}=$ global stiffness and mass matrices;

$\mathbf{K}_{u}=$ full state feedback gain matrix for deterministic regulator problem;

$\mathbf{K}^{\mathrm{el}}, \mathbf{M}^{\mathrm{el}}=$ element stiffness and mass matrices;

$\hat{\mathbf{K}}, \hat{\mathbf{M}}=$ stiffness and mass matrices for evaluation model;

$k=$ discrete-time index;

$\mathbf{L}=$ observer measurement gain matrix;

$L=$ length of main span of bridge;

$L_{x}=$ projected length of cables in $X-Z$ plane;

$M_{0 b}^{\max }, M_{0 d}^{\max }=$ maximum uncontrolled moment at base (and deck level) of two towers;

$M_{\mathrm{bi}}(t), M_{\mathrm{di}}(t)$

$=$ moment at base (and deck level) of $i$ th tower;

$\left\|M_{0 b}(t)\right\|,\left\|M_{0 d}(t)\right\|$

$=$ maximum of normed value of uncontrolled moment at base (and deck level) of towers;

$M_{l}=$ mass of lumped masses used in deck model;

$m_{i}=$ mass of the $i$ th element of deck in model;

$\widetilde{\mathbf{N}}=$ matrix used in solution of algebraic Riccati equation for LQR controller;

$\mathbf{P}_{a}=$ load vector;

$\underset{\sim}{\mathbf{P}}=$ solution of algebraic Riccati equation for LQR controller;

$P_{i}(t)=$ instantaneous power required by $i$ th control device;

$\mathbf{Q}=$ regulated output weighting matrix for $L Q R$ controller design;

$\mathbf{R}=$ control effort weighting matrix used in LQR controller design;

$\widetilde{\mathbf{R}}=$ matrix used in solution of algebraic Riccati equation for $\mathrm{LQR}$ controller;

$\underset{\sim}{\mathbf{R}}=$ matrix used in solution of algebraic Riccati equation for Kalman estimator;

$r=$ distance from lumped masses, perpendicular to axis under consideration in correction of mass moment of inertia of deck;

$r_{i}=$ distance from $i$ th element of deck, perpendicular to axis under consideration in correction of mass moment of inertia of deck;

$\mathbf{S}=$ solution of algebraic Riccati equation for Kalman estimator;

$S_{v_{i} v_{i}}, S_{\ddot{x}_{g} \bar{x}_{g}}=$ autospectral density function of measurement noise and of ground acceleration;

$\mathbf{T}_{R}=$ transformation matrix for condensation;

$T=$ discrete-time step;

$T_{0 i}(t)=$ nominal pretension in $i$ th cable;

$T_{a i}(t)=$ actual tension in cable;

$T_{f i}=$ ultimate load of $i$ th stay cable;

$T_{c}=$ cable tension;

$t=$ time variable;

$t_{i}=$ thickness of each element of deck cross section used to obtain pure torsion constant of deck $J_{t}$;

$t_{f}=$ final time of simulation;

$\mathbf{U}=$ displacement vector of bridge model;

$\hat{\mathbf{U}}=$ displacement vector of active DOF;

$\overline{\mathbf{U}}=$ displacement vector of dependent DOF;

$\mathbf{u}_{k}=$ discrete-time control command signal vector;

$u_{i}^{k}(t)=$ time response of $i$ th component of control signal;

$\mathbf{v}=$ sensor noise;

$w=$ weight per unit length of cables;

$W=$ seismic weight of bridge (not including foundation);

$\mathbf{x}=$ general state vector to describe analysis tool;

$\mathbf{x}_{k}^{c}=$ discrete-time state vector of control algorithm at time $t=k T$;

$\mathbf{x}^{d}=$ continuous-time state vector of control devices model;

$\mathbf{x}^{r}=$ continuous-time state vector of reduced order (design) model;

$\hat{\mathbf{x}}^{r}=$ Kalman filter estimate for state vector of reduced order (design) model;

$\mathbf{x}^{r}=$ continuous-time state vector of reduced order (design) model;

$\mathbf{x}^{s}=$ continuous-time state vector of sensor model;

$x_{0}^{\max }=$ maximum uncontrolled displacement at top of tower relative to ground;

$\dot{x}_{0}^{\max }=$ maximum uncontrolled velocity at top of tower relative to ground;

$\ddot{x}_{g}=$ ground acceleration;

$\mathbf{y}_{c}=$ continuous-time connection output from evaluation model to devices model;

$\mathbf{y}_{e}=$ continuous-time evaluation outputs from evaluation model;

$\mathbf{y}_{f}=$ continuous-time force output vector from control devices model;

$\mathbf{y}_{k}^{s}=$ discrete-time output vector from sensor model;

$\mathbf{y}_{m}=$ continuous-time measured output vector used for feedback;

$\mathbf{y}^{s}=$ continuous-time output from sensor model;

$y_{i}^{d}(t)=$ time response of stroke of $i$ th control device; 


$$
\begin{aligned}
\mathbf{z}= & \text { vector of regulated outputs for reduced } \\
& \text { order (design) model; } \\
\Gamma= & \text { coefficient vector relating ground } \\
& \text { acceleration input to longitudinal bridge } \\
& \text { DOFs; } \\
\hat{\Gamma}= & \text { ground acceleration coefficient vector in } \\
& \text { evaluation model; } \\
\Gamma_{w}= & \text { warping constant of deck; } \\
\gamma= & \text { ratio of autospectral density of } \ddot{x}_{g} \text { to } \\
& \text { autospectral density of sensor noise; } \\
\Delta_{j}= & \text { correction values of mass moment of inertia } \\
& \text { of deck with } j=X, Y, Z ; \\
\Delta_{X}, \Delta_{Y}, \Delta_{Z}= & \text { correction values of mass moment of inertia } \\
& \text { of deck; } \\
\Lambda= & \text { vectors of ones and zeros defining how } \\
& \text { forces of control devices are input to bridge; } \\
& \text { and } \\
\hat{\Lambda}= & \text { control force coefficient matrix in evaluation } \\
& \text { model. }
\end{aligned}
$$

\section{References}

ABAQUS (1998). Hibbitt, Karlsson and Sorensen Inc., Pawtucket, R.I. Antoniou, A. (1993). Digital filters: Analysis, design, and applications, McGraw-Hill, New York, 444-446.

Bleich, F. (1952). Bucking strength of metal structures, McGraw-Hill, New York.

Caicedo, J. M., Dyke, S. J., Turan, G., and Bergman, L. A., (2000). "Comparison of modeling techniques for dynamic analysis of a cablestayed bridge." Proc., Engineering Mechanics Conf. ASCE, Austin, Tex. May 21-23.

Caughey, T. K. (1998). “The benchmark problem." Earthquake Eng. Struct. Dyn., 27, 1125.

Çelebi, M. (1999), Seismic Instrumentation of the Girardeau (MO) Cable-stayed Bridge, Proc., Mid-America Seismic Highway Conference, St. Louis, Missouri, 28 February-3 March.

Chen, J-C., ed. (1996). Proc., 2nd Int. Workshop on Structural Control: Next Generation of Intelligent Structures, Research Centre, The Hong Kong Univ. of Science and Technology, Hong Kong, Hong Kong (see: 〈http://cwis.usc.edu/dept/civil_eng/structural/welcome.html〉).
Craig, Jr., R. R. (1981). Structural dynamics, an introduction to computer methods, Wiley, New York.

Ernst, H. J. (1965). "Der E-Modul von Seilen unter Berucksichtigung des Durchhanges." Der Bauingenieur, 40(2), 311-323 (in German).

Hague, S. (1997). "Composite design for long span bridges." Proc. of the XV ASCE Structures Congress, Portland, Ore.

MATLAB (1997). The Math Works, Inc., Natick, Mass.

Ohtori, Y., Christenson, R., Spencer, Jr., B. F., and Dyke, S. J. (2003). "Benchmark control problems for seismically-excited nonlinear buildings." J. Eng. Mech., in press.

Ohtori, Y., and Spencer, B. F., Jr. (1999). "A MATLAB-based tool for nonlinear structural analysis." Proc., 13th Engineering Mechanics Conf., Baltimore, June 13-16.

Quast, P., Spencer, Jr., B. F., Sain, M. K., and Dyke, S. J. (1995). "Microcomputer implementation of digital control strategies for structural response reduction." Microcomput. Civ. Eng., 10, 13-25.

Schemmann, A. G., Smith, H. A., Bergman, L. A., and Dyke, S. J. (1998). "Feasibility study: Control of a cable-stayed bridge model. I: Problem definition." Proc., 2nd Int. Conf. on Structural Control, Vol. 2, Wiley, England, 975-979, Kyoto, Japan, June 30-July 2.

SIMULINK (1997). The Math Works, Inc., Natick, Mass.

Skelton, R. E. (1988). Dynamic systems control: Linear systems analysis and synthesis, Wiley, New York.

Spencer Jr., B. F., Christenson, R. E., and Dyke, S. J. (1998b). "Next generation benchmark control problem for seismically excited buildings." Proc., Second World Conf. on Structural Control, Kyoto, Japan, June 29-July 2, 1351-1360 (also see: 〈http://www.nd.edu/ quake/)).

Spencer, Jr., B. F., Dyke, S. J., and Deoskar, H. S. (1998a). "Benchmark problems in structural control. I: Active mass driver system and Part II: Active tendon system." Earthquake Eng. Struct. Dyn., 27, $1127-$ 1147.

Stengel, R. F. (1986). Stochastic optimal control: Theory and application, Wiley, New York.

Wilson, J., and Gravelle, W. (1991). "Modelling of a cable-stayed bridge for dynamic analysis." Earthquake Eng. Struct. Dyn., 20, 707-721.

Yang, J. N., Agrawal, A. K., Samali, B., and Wu, J. C. (2003). "Benchmark problem for response control of wind-excited tall buildings." $\mathrm{J}$. Eng. Mech., in press.

Yang, J. N., Wu, J. C., Samali, B., and Agrawal, A. K. (1998). "A benchmark problem for response control of wind-excited tall buildings." Proc., 2nd World Conf. on Structural Control, Kyoto, Japan (also see 〈http://www.eng.uci.edu/ anil/benchmark.html〉). 